\title{
Natural IgG antibodies provide innate protection against ficolin-opsonized bacteria
}

\section{Saswati Panda ${ }^{1}$, Jing Zhang ${ }^{2,7}$ \\ Nguan Soon Tan ${ }^{3,4,8}$, Bow How,8 and Jeak Ling Ding ${ }^{1,6,8, *}$}

\begin{abstract}
${ }^{1}$ Department of Biological Sciences, Faculty of Science, National University of Singapore, Singapore, Singapore, ${ }^{2}$ NUS Graduate School for Integrative Science and Engineering, National University of Singapore, Singapore, Singapore, ${ }^{3}$ School of Biological Sciences, Nanyang Technological University, Singapore, Singapore, ${ }^{4}$ Institute of Molecular and Cell Biology, Proteos, Singapore, ${ }^{5}$ Department of Microbiology, Yong Loo Lin School of Medicine, National University of Singapore, Singapore, Singapore and ${ }^{6}$ Singapore MIT Alliance, National University of Singapore, Singapore, Singapore
\end{abstract}

For nearly five decades since its discovery, the role of natural IgG, which pre-exists in neonates and uninfected individuals, has remained unclear due to the general perception that natural antibodies lack affinity for pathogens. Here, we show for the first time that natural IgG recognizes a spectrum of bacteria through lectins like ficolin and mannose binding lectin (MBL). Infection-inflammation condition markedly increased the affinity of natural IgG for bacteria associated with ficolins. After opsonization with IgG:ficolin complex, the bacteria were phagocytosed by monocytes via Fc $\gamma$ RI. Infection of $C 3^{-/-}$ mice indicated that the natural IgG-mediated immune complex was formed independently of $\mathrm{C} 3$. $A I D^{-/-}$mice lacking IgG were susceptible to infection, unless reconstituted with natural IgG. Thus, we have proven that natural IgG is not quiescent; rather, it plays a vital and immediate role in immune defense. Our findings provide a fresh perspective on natural antibodies, opening new avenues to explore host-microbe interaction.

The EMBO Journal (2013) 32, 2905-2919. doi:10.1038/

emboj.2013.199; Published online 3 September 2013

Subject Categories: immunology

Keywords: bacterial recognition; IgG:lectin immune complexes; infection-inflammation condition; lectins; natural antibodies

\section{Introduction}

A repertoire of natural antibodies comprising IgM, IgG, and IgA pre-exist in the serum of newborns (Hardy and Hayakawa, 1994) and germ-free animals (Sidman et al, 1986) in the absence of any foreign antigenic stimulation. They react with a wide variety of self-antigens, including

\footnotetext{
*Corresponding author. Department of Biological Sciences, Faculty of Science, National University of Singapore, 14 Science Drive 4, Singapore, Singapore 117543, Singapore. Tel.: +65 6516 2776; Fax: +65 6779 2486; E-mail: dbsdjl@nus.edu.sg

${ }^{7}$ Present address: Department of Physiology, Michigan State University, 4155 Biomedical Physical Science Building, Lansing, MI 48824, USA.

${ }^{8} \mathrm{Co}$-senior authors.
}

Received: 9 April 2013; accepted: 8 August 2013; published online: 3 September 2013 nuclear antigens, intracellular and membrane components, and circulating plasma proteins (Avrameas, 1991; Ehrenstein and Notley, 2010). In contrast to the antigen-specific antibodies that are produced by mature B cells through somatic hypermutation (SHM) in a T-cell dependent pathway in response to a foreign pathogenic challenge (Muramatsu et al, 1999), natural antibodies are non-antigen specific towards pathogens (Avrameas, 1991) and are produced by innate-like B cells like B1, B2, and marginal zone (MZ) B cells in a T-cell independent (TI) manner. A fraction of natural antibodies may however originate from MZ B cells that undergo SHM via TI pathways, giving rise to mutated variable regions even in the absence of an infection (Reynaud et al, 1995; Toellner et al, 2002). However, among the natural antibody isotypes, natural IgM has been shown to bind non-specifically to a wide range of microbes by virtue of its flexible antigen-binding region and pentameric structure (Zhou et al, 2007). This unique property of natural IgM enables it to activate the complement cascade, trap pathogens in lymphoid organs, and perform immunoregulatory functions (Ehrenstein and Notley, 2010). Despite extensive studies on natural IgM, the fundamental role and mechanism of action of natural IgG and IgA isotypes, which constitute the majority of the natural antibodies, have remained enigmatic for nearly five decades of their discovery (Boyden, 1966; Michael, 1969).

On the basis of the previous observation that IgA and M-ficolin interact (Zhang et al, 2010), and considering the low affinity of both the natural IgG and IgA for antigens, we hypothesized that these natural antibodies might act in an indirect manner, most likely through interaction with ficolins, a member of the lectin family that bind to pathogens directly. Ficolins and mannose binding lectin (MBL) are the major serum lectins belonging to the soluble class of patternrecognition receptors (PRRs). They recognize microbes through various pathogen pattern-associated molecular patterns (PAMPs), like lipopolysaccharide (LPS), lipoteichoic acid (LTA), and 1,3- $\beta$-D-glucan (Dempsey et al, 2003). Ficolins and MBL are known to play a crucial role in preventing bacterial sepsis and necrotizing enterocolitis in neonates (Schlapbach et al, 2010, 2011). Both ficolins and MBL comprises a fibrinogen-like (FBG) domain and a collagenlike domain (CD). The FBG domain binds to $\mathrm{N}$ acetylglucosamine (GlcNAc), a moiety conserved in PAMPs (Matsushita et al, 1996).

Several reports have indicated lower $\mathrm{pH}$ values (5.5-7.0) in the microenvironment around trauma-induced infection (Baranov and Neligan, 2007), acute renal failure (Zar et al, 2007), intra-abdominal infection (Simmen et al, 1994), and tissue abscesses (Bessman et al, 1989). Lower calcium concentration $(\leqslant 2 \mathrm{mM})$ has also been reported in the infected microenvironment (TranVan Nhieu et al, 2004; Prince et al, 2006; Eichstaedt et al, 2009). Infection-induced inflammation resulting in acidosis and reduction in calcium levels have been shown to facilitate the interaction between 
PRRs to boost antimicrobial response (Zhang et al, 2009). When tested in the range of $\mathrm{pH}$ 5.5-7.4, the innate immune proteins exhibit strongest binding at $\mathrm{pH} 6.5$ (Zhang et al, 2011). In the present study, we have explored the in vitro interaction between natural IgG and ficolins under two conditions: (1) the physiological 'normal condition' ( $\mathrm{pH} 7.4$ and $2.5 \mathrm{mM}$ calcium) that exists in the serum and (2) the 'infection-inflammation condition' in the tissue microenvironment ( $\mathrm{pH} 6.5$ and $2.0 \mathrm{mM}$ calcium). To simulate these conditions, we employed specific buffers previously used by others (Miyazawa and Inoue, 1990; Gu and Lee, 2006; Zhang et al, 2009; Liu et al, 2011).

In this study, we explored the biological function of natural IgG in evoking host-microbe interaction during an immune response. We observed that the pool of natural IgG purified from uninfected serum, and the representative individual populations of natural IgG such as anti-alpha gal IgG (isolated from human serum) and IgG3 (purified from nude mice serum), all specifically interact with lectins (e.g., ficolins and MBL), which were bound to bacteria. We found that infection-inflammation condition increased the affinity between natural IgG and ficolin, and enhanced the phagocytosis of bacteria opsonized with IgG:ficolin complex, and this occurs independently of complement C3. The importance of ficolin in aiding natural IgG function was ascertained in vivo by blocking the IgG:ficolin complex formation using competitive ficolin-binding IgG peptides, which compromised mice survival post infection. The physiological role of natural IgG was further confirmed by infection of $A I D^{-/-}$ mice (lacking IgG), which showed a higher mortality unless protected by reconstitution with purified natural IgG prior to infection. Collectively, our findings bridge a half-century gap of knowledge about the functional existence and contribution of natural antibodies to immunity. Our findings should dispel the perception that natural IgG is non-reactive. It opens new avenues to explore host-microbe interaction and innate immune response.

\section{Results}

\section{Natural IgG interacts with ficolin bound on bacteria, enhanced by infection-inflammation condition}

Infection-induced drop in $\mathrm{pH}$ (from 7.4 to 6.5) and calcium levels (from 2.5 to $2.0 \mathrm{mM}$ ) has been shown to boost the interaction between innate immune proteins (Zhang et al, 2011). When we characterized IgG:ficolin interaction at various $\mathrm{pH}(5.0-7.4)$ and calcium concentrations (0-5 mM), we observed strongest binding at $\mathrm{pH} 6.5$ and $2.0 \mathrm{mM}$ calcium (Supplementary Figure S1A), suggesting that mild acidosis and hypocalcaemia triggers IgG:ficolin interaction. Henceforth, we used two conditions to study the natural IgG:ficolin interaction in vitro: (1) the physiological 'normal condition' (pH 7.4 and $2.5 \mathrm{mM}$ calcium) and (2) the 'infection-inflammation condition' ( $\mathrm{pH} 6.5$ and $2.0 \mathrm{mM}$ calcium).

Natural IgG has been defined as the total repertoire of IgG in the serum of animals and individuals not previously exposed to any foreign antigen (Ochsenbein et al, 1999). There are three predominant serum IgG isotypes: IgG1, IgG2, and IgG3 (Supplementary Figure S1B) of which IgG3 is the natural IgG (Michael, 1969; Sidman et al, 1986). Since preliminary evidence showed that IgG and IgA interact with ficolins (Zhang et al, 2010; unpublished data), we compared the binding of all three IgG isotypes to ficolin pre-bound to the bacterial mimic (GlcNAc). Interestingly, we found that IgG3 specifically exhibited dose-dependent binding to ficolin with a significant increase under infection-inflammation condition (Figure 1A). Next, we examined the ability of IgG purified from uninfected human serum to recognize representative Gram-negative (Pseudomonas aeruginosa, P.a. and Escherichia coli, E.c.) and Gram-positive (Staphylococcus aureus, S.a. and Staphylococcus epidermidis, S.e.) bacteria in the presence and absence of ficolins. We found that IgG by itself did not bind to any of the bacteria tested (Figure 1B; Supplementary Figure S1C, red) but was deposited dose dependently on all three isoforms of ficolin pre-bound to the bacteria (Supplementary Figure S2), with maximum deposition enabled by H-ficolin (Figure 1B; Supplementary Figure S1C). The differential ability of the ficolins (L-, M-, and $\mathrm{H}$-ficolin isoforms) to enable the deposition of natural IgG onto the bacteria is likely due to the subtle differences in the amino-acid composition of the FBG domains of the ficolins (Zhang et al, 2009). Deviation observed with S. aureus is explained by the presence of Protein A on its surface, which is a known ligand of IgG (Graille et al, 2000).

Notably, the infection-inflammation condition induced a 3.5-fold increase in the recruitment of IgG onto the bacterial mimic, that is, GlcNAc-Sepharose beads (GlcNAc-beads), with the aid of ficolin (Figure 1C, '+ GlcNAc'). IgG did not

Figure 1 Natural IgG, aided by ficolin, recognizes bacteria-infection-inflammation enhances IgG:ficolin affinity. (A) ELISA to show binding of IgG isotypes, present in uninfected serum, or purified total IgG, to ficolin on immobilized GlcNAc, under normal and infection-inflammation conditions. (B) FACS quantification of the binding of purified human IgG to $10^{6}$ c.f.u. bacteria. Bacteria were incubated with IgG alone or IgG $+0.5 \mu \mathrm{g}$ or IgG $+1 \mu \mathrm{g}$ ficolin. Bacteria opsonized with antigen-specific IgG and secondary antibody alone served as positive and negative controls, respectively. For FACS plots, see Supplementary Figure S1B. The panel compares the mean fluorescence intensity (MFI) of IgG bound to the bacteria incubated with IgG alone or IgG $+1.0 \mu \mathrm{g} / \mathrm{H} / \mathrm{M}$-ficolin. Three independent experiments with three replicates each were performed per sample/condition tested. ${ }^{*} P<0.05 ;{ }^{*} P<0.01$; n.s., not significant. (C) Co-IP to determine the interaction between IgG and $\mathrm{H}$-ficolin on the bacterial mimic in human serum. GlcNAc-Sepharose beads (+ GlcNAc) were incubated with serum repleted with or depleted of GlcNAc-binding lectins under normal (white bar) and infection-inflammation conditions (black bar). Sepharose beads alone ( - GlcNAc) was the negative control. A representative western blot shows ratio of the density of IgG:H-ficolin deposited on beads. (D) Immunoblot of IgG and ficolin purified from uninfected human serum. Serum simulated under infection-inflammation condition yielded IgG:ficolin complex. rFicolin is recombinant ficolin. Anti-human IgG detected both the heavy ( $50 \mathrm{kDa})$ and light $(25 \mathrm{kDa})$ chains of IgG. (E) SPR analysis of the binding affinity between purified human IgG and H-ficolin FBG on GlcNAc under normal and infection-inflammation conditions. GlcNAc was immobilized on CM5 chip followed by injection of $\mathrm{H}$-ficolin FBG for $750 \mathrm{~s}$ (association time) and buffer for $750 \mathrm{~s}$ (dissociation time). Increasing concentrations of IgG were injected over the bound FBG under similar run conditions. Cartoon illustrates the order of binding. Negative controls: HSA injected after ficolin FBG; IgG injected over GlcNAc-immobilized chip (blue), both showed no binding. (F) SPR analysis of the binding affinity between H-ficolin FBG and IgG on Fc $\gamma$ RI. IgG was injected over Fc $\gamma$ RI-immobilized CM5 chip followed by buffer under similar run conditions as described in (E). Increasing concentrations of FBG were injected over bound IgG. Cartoon illustrates the order of binding. Negative controls: HSA injected after IgG injection and FBG injected over the Fc $\gamma$ RI-immobilized chip, both showed no binding (blue). Results represent the data from three independent experiments. Source data for this figure is available on the online supplementary information page. 
bind to Sepharose beads alone (-GlcNAc), or to GlcNAc beads in serum depleted of GlcNAc-binding lectins like ficolin. Furthermore, we observed that IgG and ficolin were not co-purified but were isolated separately from uninfected human serum. Only when the serum was simulated under infection-inflammation condition ( $\mathrm{pH}$ 6.5, $2.0 \mathrm{mM}$ calcium), IgG and ficolin were co-purified as an IgG:ficolin complex on GlcNAc beads (Figure 1D). Consistently, under infection- inflammation condition, IgG exhibited stronger and specific dose-dependent binding to the FBG domain of all three ficolins (L, H, and $\mathrm{M}$ isoforms), which were pre-bound to GlcNAc immobilized on ELISA plates (Supplementary Figure S2). Moreover, IgG exhibited similar binding characteristics to both the full-length ficolin and the FBG domain of ficolin. This is consistent with other reports that FBG is the functional interactive domain of ficolins (Ng et al, 2007; Ma et al,
A
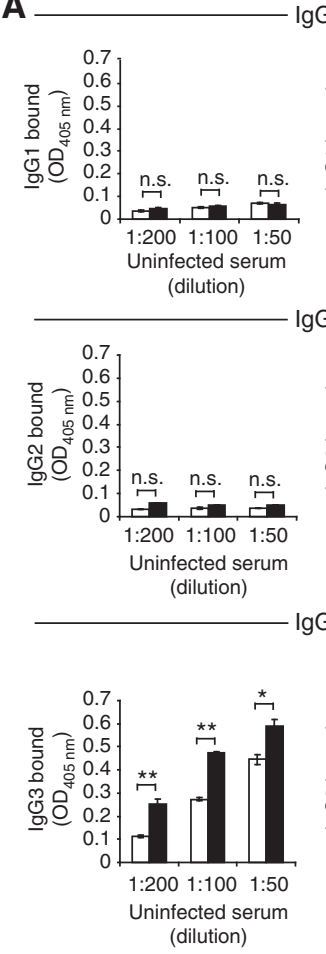

$\lg G 3$
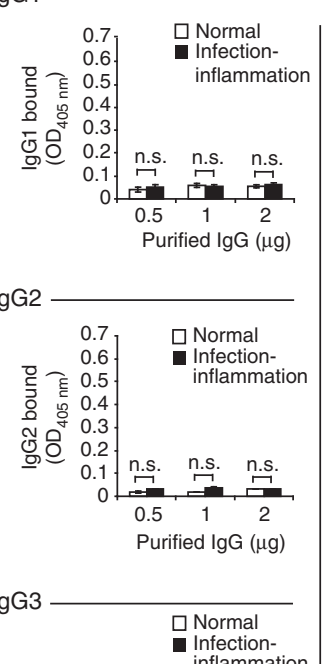

E
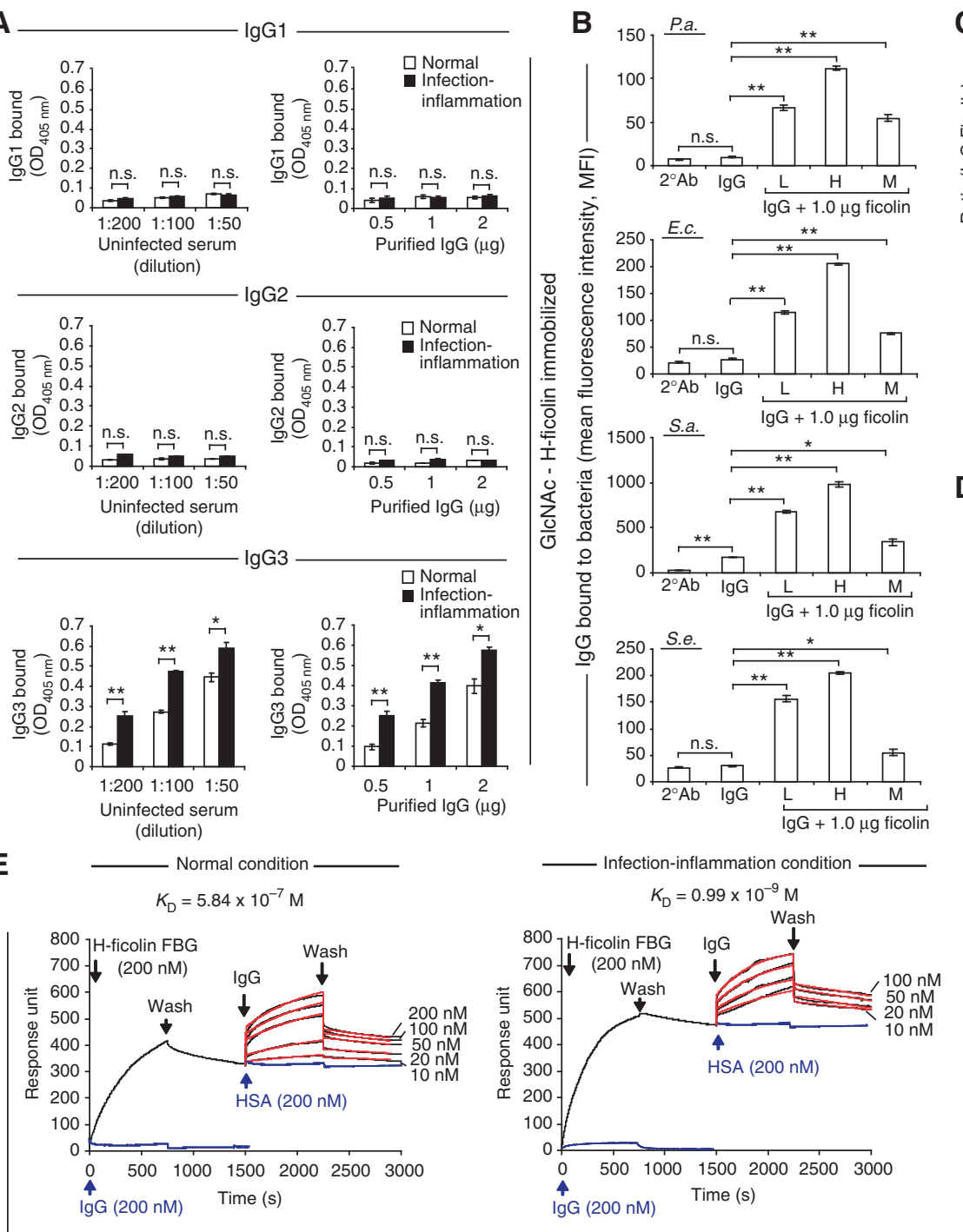

GlcNAc immobilized on CM5 chip

$\mathbf{F}$

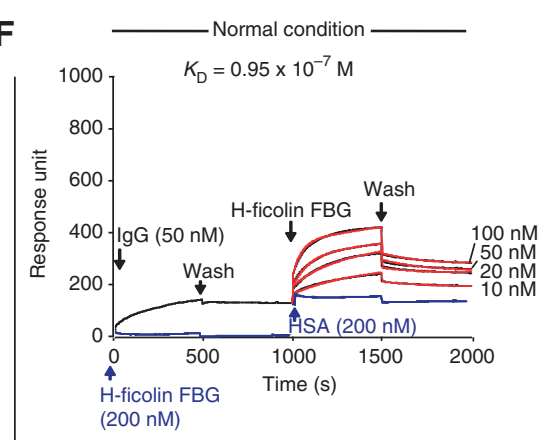

C

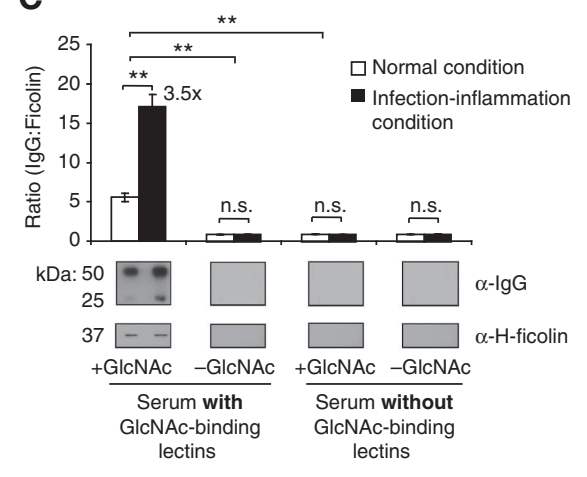

D

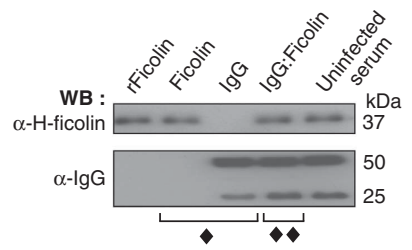

- Proteins purified seperately from uninfected serum $\left(\mathrm{pH} 7.4,2.5 \mathrm{mM} \mathrm{Ca}^{2+}\right)$

$\checkmark$ IgG: Ficolin complex purified from uninfected serum simulated under infectioninflammation condition $\left(\mathrm{pH} 6.5,2.0 \mathrm{mM} \mathrm{Ca}^{2+}\right.$ )
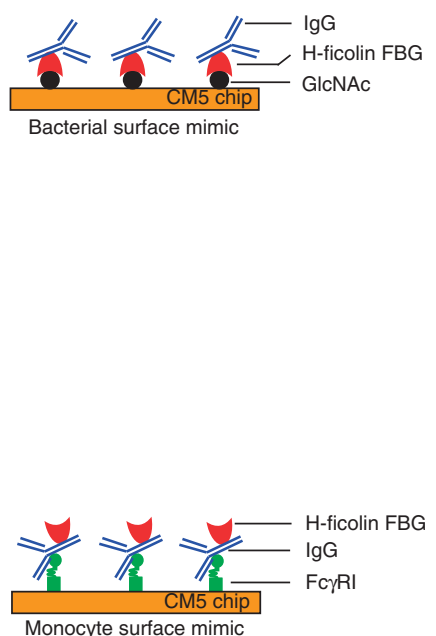

Fc $\gamma \mathrm{RI}$ immobilized on CM5 chip 
2009; Zhang et al, 2009). These results indicate that natural IgG specifically binds ficolin associated with PAMPs through its FBG domain, and that the binding was enhanced under infection-inflammation condition.

\section{Infection-inflammation condition increases the affinity between natural IgG and ficolin}

Having shown that natural IgG plays an important functional role aided by ficolin, it was pertinent to characterize the molecular interaction between natural IgG and ficolin. First, we performed surface plasmon resonance (SPR) analysis on GlcNAc-immobilized chip (mimicking the bacterial surface). All three ficolin FBGs exhibited similar affinity for GlcNAc regardless of normal or infection-inflammation condition (Supplementary Figure S3), thus providing a uniform basis for our subsequent study of the affinity of interaction between immobilized FBG and IgG. Injection of IgG under infection-inflammation condition, over the immobilized ficolin FBG, showed a 100-fold increased affinity between IgG:ficolin compared with normal condition (Figure 1E). Next, we studied the IgG:ficolin interaction on Fc $\gamma$ RI-immobilized chip (mimicking the phagocytic surface of monocytes). After binding IgG to Fc $\gamma$ RI, the H-ficolin FBG was introduced. Figure $1 \mathrm{~F}$ shows that infection-inflammation condition induced a 100-fold higher affinity between IgG:ficolin, consistent with the interaction on the bacterial mimic under similar condition (Figure 1E). The ficolin FBG itself did not bind Fc $\gamma$ RI, and the negative control, human serum albumin (HSA) did not bind IgG (Figure 1F, blue), supporting the specificity of the assembly of IgG:ficolin on monocyte Fc $\gamma$ RI. These results suggest that the biophysical interaction between natural IgG and ficolin appears to be tunable based on the infection-inflammation condition (lowered $\mathrm{pH}$ and calcium levels) - the observed $K_{\mathrm{D}}$ becomes 100 fold tighter when the $\mathrm{pH}$ was lowered from 7.4 to 6.5. This high affinity binding of the immune complexes on the bacteria ensures effective recognition and opsonization of the microbe.

\section{IgG:ficolin complex-opsonized bacteria is phagocytosed by monocytes via FcyRI}

Next, we studied the uptake of $P$. aeruginosa opsonized with individual proteins or the natural IgG:ficolin complex by human primary monocytes, and examined the ensuing immune response. We found that natural IgG alone was ineffective in opsonization and hence unable to initiate bacterial phagocytosis. In contrast, the natural IgG:ficolin complex induced bacterial phagocytosis, and infection-in- flammation condition enhanced the clearance, particularly of bacteria opsonized with natural IgG:H-ficolin complex (Figure 2A). Thus henceforth, we focussed on IgG:H-ficolin mediated action, unless otherwise stated. There are three known Fc $\gamma$ R receptors (Fc $\gamma$ RI, Fc $\gamma$ RII, and Fc $\gamma$ RIII), out of which Fc $\gamma$ RI has the highest affinity for IgG-opsonized bacteria and immune complexes (Burton et al, 1988; Indik et al, 1995). Hence, we specifically knocked down Fc $\gamma R I$ in human monocytes (Figure 2B), and observed a significant reduction in the phagocytosis of IgG:ficolin opsonized bacteria (Figure 2A, blue). In this experiment, we used GlcNAc beads as a bacterial mimic instead of whole bacteria since ficolin specifically recognizes GlcNAc, hence allowing us to query the response resulting directly from natural IgG:ficolin mediated recognition, rather than by other PRRs. We found that phagocytosis of IgG:ficolin opsonized GlcNAc beads markedly induced IL8 (Figure 2C), which is a pro-inflammatory chemokine upregulated during Fc $\gamma$ RI-mediated phagocytosis of $P$. aeruginosa by monocytes (Marsh et al, 1996; Kube et al, 2001). Similar profiles were observed with other pro-inflammatory cytokines like TNF $\alpha$ and IL6 and anti-inflammatory cytokine IL10 post stimulation (Supplementary Figure S4). Congruent to reduced phagocytosis, monocytes knocked down of $F c \gamma R I$ produced significantly less IL8, confirming that Fc $\gamma$ RI is involved in phagocytosis of the natural IgG:ficolin opsonized bacteria, leading to pro-inflammatory response.

When we tracked the molecular interaction of IgG:ficolin immune complex with Fc $\gamma$ RI on the monocytes, we found that only the IgG:ficolin opsonized GlcNAc beads were colocalized on monocytes, whereas ficolin alone proved to be inefficient (Figure 2D; Supplementary Figure S5A). Proximity ligation assay (PLA) further demonstrated proteinprotein interactions in situ, displaying an assembly of ficolin, IgG, and Fc $\gamma R I$ on the monocyte surface (Figure 2E; Supplementary Figure S5B). Ficolin was brought into proximity with Fc $\gamma$ RI only in the presence of IgG, confirming the importance of natural IgG in bridging the ficolin bound on pathogen to Fc $\gamma$ RI on the monocytes. Infection-inflammation condition induced a significant increase in IgG:ficolin complexes (Figure 2E). The lack of interaction between IgG and HSA on the monocytes (Supplementary Figure S5C), and the absence of IgG:ficolin complexes on HEK293T cells, which are deficient in Fc $\gamma$ RI (Supplementary Figure S5D), indicated the specificity of interaction between IgG, ficolin, and Fc $\gamma$ RI on the monocytes. Figure $2 \mathrm{~F}$ suggests how natural IgG mediates recognition of bacteria bound to ficolin via Fc $\gamma$ RI on a phagocyte, facilitating the clearance of the invading microbe.

Figure 2 Infection inflammation increases the natural IgG-mediated bacterial phagocytosis through monocyte Fc $\gamma$ RI and upregulates IL8. (A) FACS quantification of phagocytosis of $10^{7}$ c.f.u. GFP P. aeruginosa (opsonized with the proteins, individually or in complex) by $10^{6}$ human primary monocytes under normal (green) and infection-inflammation conditions (red). 1:10 diluted serum is the positive control; natural antibody effect was masked due to dilution. Fc $\gamma I$ knockdown in human monocytes significantly reduced phagocytosis (blue). (B) Knockdown of Fc $\gamma R I$ by nucleofection of $10^{6}$ monocytes with either control or Fc $\gamma$ RI-specific siRNA for $72 \mathrm{~h}$. (C) ELISA quantifies IL8 secretion by $10^{6}$ monocytes (with or without Fc $\gamma R I$ knockdown) incubated with GlcNAc beads opsonized with both IgG and ficolin for $24 \mathrm{~h}$. Monocytes incubated without GlcNAc beads or with proteins alone are negative controls. Three independent experiments with three replicates each were performed per sample/condition tested. ${ }^{*} P<0.05$; ${ }^{*} P<0.01$; n.s., not significant. (D, E) Cellular localization of IgG:ficolin complex. Human monocytes were incubated with GlcNAc beads opsonized with proteins (indicated on the left). (D) Confocal microscopy shows co-localization of H-ficolin (red) and IgG (green) or H-ficolin (red) and Fc $\gamma$ RI (green). Nuclei were stained with DAPI (blue). $\times 100$ objective; scale bar, $10 \mu \mathrm{m}$. Co-localization was quantified by scatter plots using Pearson's correlation (R) and overlap co-efficient (OC). (E) Quantification of IgG:H-ficolin, IgG:Fc $\gamma$ RI, and H-ficolin ( \pm IgG):Fc $\gamma$ RI interactions in situ by PLA. $\times 100$ objective. Scale bar, $5 \mu \mathrm{m}$. Red dots per cell were scored using the Image J software. Duplicates of 50 cells were enumerated per condition tested for three independent experiments. (F) Diagrammatic representation suggesting how natural IgG:ficolin:Fc $\gamma R I$ interaction clears the invading microbe by phagocytosis, with production of IL8. Results represent the data from three independent experiments. Source data for this figure is available on the online supplementary information page. 


\section{In vivo studies with WT mice confirmed that natural IgG recognizes bacteria with the aid of lectins and independently of $\mathbf{C 3}$}

To validate our in vitro findings and to establish the biological significance of natural IgG in vivo, we examined the functional role of natural IgG in mice. We found that on its own, IgG purified from the sera of uninfected WT mice exhibited negligible binding to $P$. aeruginosa (Figure 3A). Addition of serum depleted of IgG (but containing all other serum proteins) facilitated the binding of the purified natural IgG to the bacteria, whereas addition of serum that was further depleted of ficolin (Figure 3A, see western blot inset) significantly reduced the recruitment of purified IgG to the bacteria. However, we still observed residual level of binding of the purified IgG to the bacteria in ficolin-depleted serum, which prompted us to check whether other major serum lectins
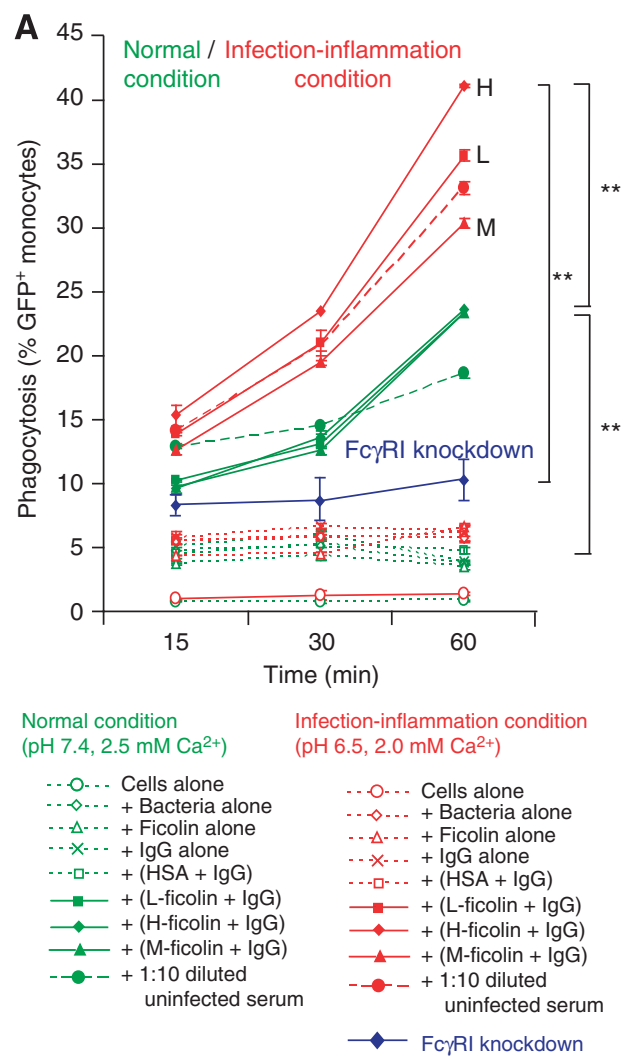

B

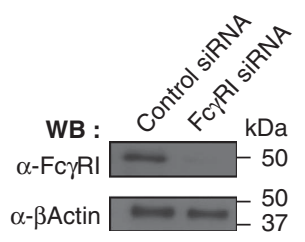

C 100

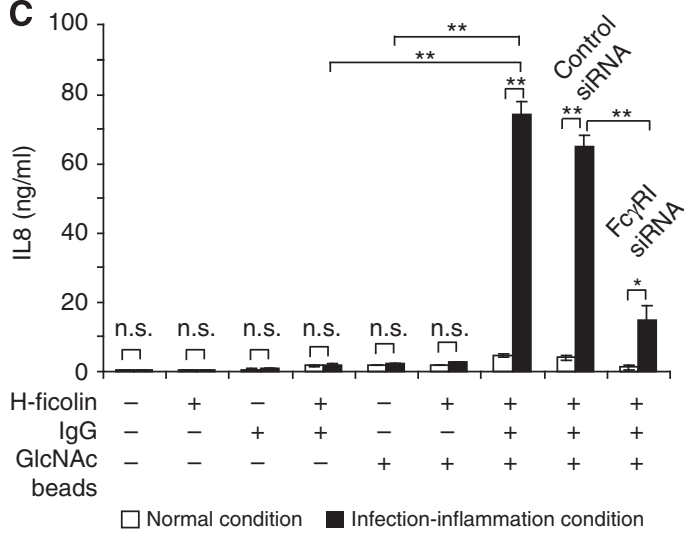

D
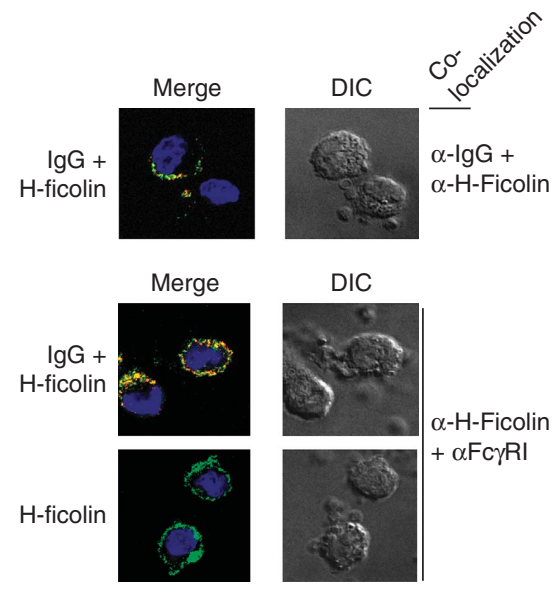

DIC

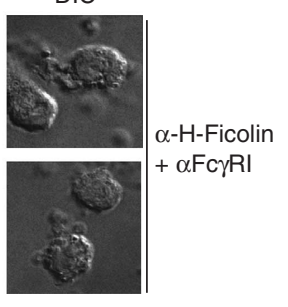

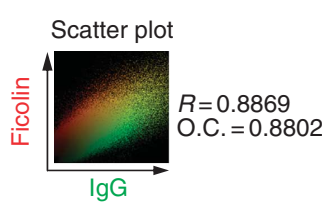

Scatter plot
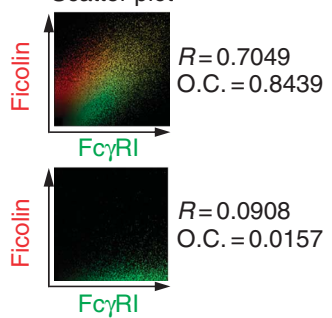

$\mathbf{E}$

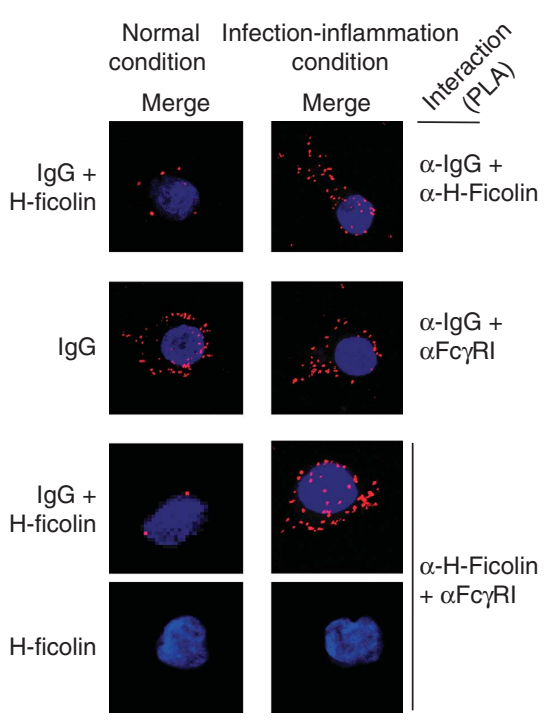

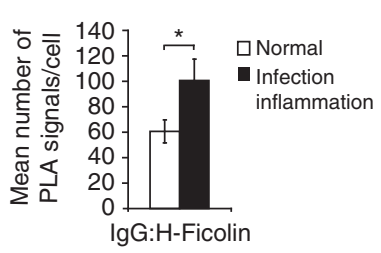
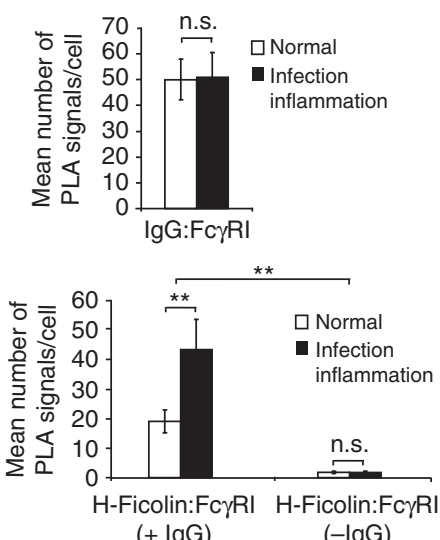

$\mathbf{F}$

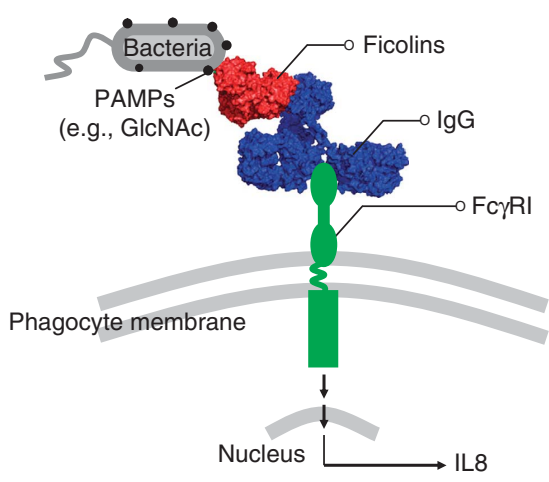
L8 

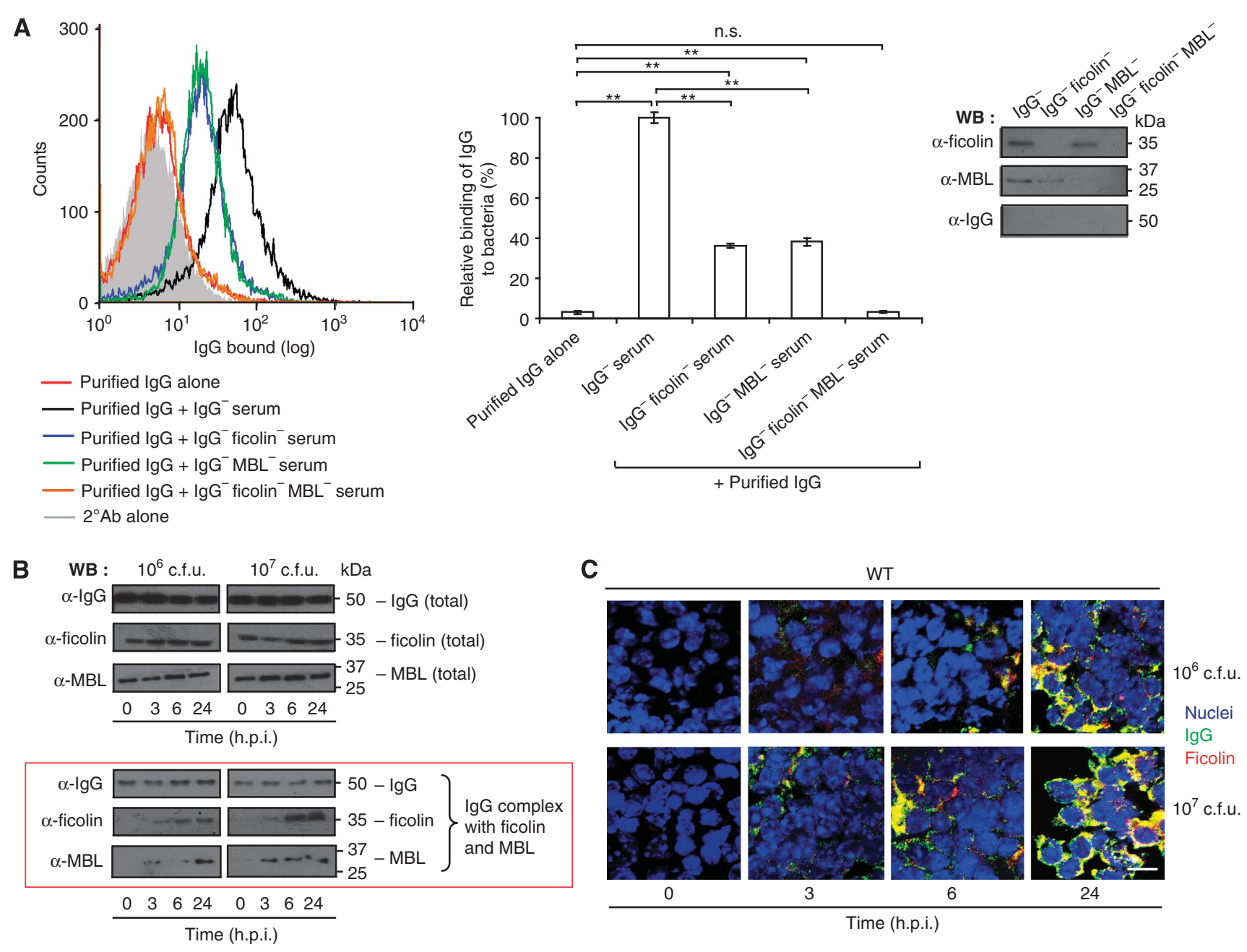

Figure 3 Natural IgG recognizes bacteria with the aid of lectins in WT mice. (A) FACS analysis to detect binding of IgG purified from pooled sera of uninfected WT mice $(n=8)$ to $10^{6}$ c.f.u. P. aeruginosa. Bacteria were incubated with purified IgG alone (red) or with purified IgG + various depleted sera (annotated below figure). The IgG bound was probed with anti-mouse IgG and corresponding Alexa 488-conjugated secondary antibody. Bacteria incubated with $2^{\circ} \mathrm{Ab}$ alone served as the negative control (grey). The right panel is a plot depicting the $\%$ binding of IgG to the bacteria relative to purified IgG $+\mathrm{IgG}^{-}$serum value (all the values were subtracted from $2^{\circ} \mathrm{Ab}$ alone value). The inset shows immunoblot detecting IgG (heavy chain, $50 \mathrm{kDa}$ ), ficolin, and MBL in pooled sera, which was first depleted of IgG and then of ficolin or MBL or both. The samples were resolved in SDS-PAGE (12\%) under reducing conditions. (B) Immunoblot detects IgG (heavy chain), ficolin, MBL, and IgG complexed with ficolin or MBL (pulled down by Protein G beads, red box) in pooled sera of WT mice $(n=8)$. Sera were obtained postinfection with $10^{6}$ or $10^{7}$ c.f.u. P. aeruginosa. (C) Immunohistochemical staining detects IgG:ficolin complexes in the spleen of WT mice ( $n=3$ ), uninfected (0 h.p.i.), and infected with P. aeruginosa. $\times 100$ objective; scale bars, $10 \mu \mathrm{m}$. Source data for this figure is available on the online supplementary information page.

such as MBL were also involved in recruiting the purified IgG onto the bacteria. Indeed, depletion of MBL from the serum partially reduced IgG binding. Notably, depletion of both ficolin and MBL abrogated the bacterial binding ability of natural IgG, corroborating that natural IgG collaborates with multiple serum lectins to recognize pathogens. We observed increasing IgG:ficolin and IgG:MBL complexes formed in the serum, in a time- and bacterial dose-dependent manner in infected WT mice (Figure 3B, red box). For further studies on natural IgG activity, we focussed our attention on its complex with ficolin (as a representative lectin), unless otherwise stated. Consistent with a report that natural antibodies target the opsonized pathogen complexes to the spleen to limit the spread of infection (Ochsenbein et al, 1999), we observed a progressive increase in IgG:ficolin complexes in the spleens of infected WT mice (Figure 3C).

It is reported that complement $\mathrm{C} 3$ alpha chain covalently interacts with IgG heavy chain in the presence of immune complexes (Sahu and Pangburn, 1994). Thus, we sought to determine whether $\mathrm{C} 3$ might play a role in the formation of IgG:ficolin complex or in fine-tuning the subsequent action of the immune complex. We first confirmed that sera from $\mathrm{C}^{-1-}$ mice, which lack C3, contained similar levels of IgG and ficolin as that of WT mice (Supplementary Figure S6A and B). Ex vivo studies using uninfected $C 3^{-/-}$mice sera showed that purified IgG was able to bind to P. aeruginosa with the aid of ficolin despite the absence of C3 (Supplementary Figure S6C). To verify this observation in vivo, we infected WT and $C 3^{-1-}$ mice with $P$. aeruginosa and examined the potential contribution of C3 in IgG:ficolin complex in the serum up to $24 \mathrm{~h}$. We found no difference in the increase in amount of IgG:ficolin complex (pulled down by Protein G beads) over the course of infection in both WT and $\mathrm{C}^{-{ }^{-}}$mice, but no $\mathrm{C} 3$ was associated with the natural IgG:ficolin complex (Supplementary Figure S6D), corroborating that the absence of $\mathrm{C} 3$ did not affect the recruitment of 
natural IgG to ficolin-bound bacteria. Similarly to the WT mice (Figure 3C), an increase in IgG:ficolin complexes in the spleen was observed over time of infection of $\mathrm{C3}^{-1-}$ mice (Supplementary Figure S6E). These results collectively confirm that C3 is not involved in natural IgG:ficolin mediated immune recognition of the invading microbe.

\section{Natural IgG protects AID ${ }^{-/-}$mice (lacking IgG) from infection}

To substantiate our in vitro and ex vivo observations on the function of natural IgG, we performed in vivo studies, using AID ${ }^{-/-}$mice, which lack class-switch recombination (Muramatsu et al, 2000) and hence harbour only IgM but not IgG and IgA (Supplementary Figure S7A and B). Upon infection with $P$. aeruginosa, we found that the bacterial burden progressively increased in various tissues of $A I D^{-/-}$ mice (Figure 4A), with substantial delay in clearance (Figure 4B). Additionally, we observed a significant increase in pro-inflammatory IL6 and TNF $\alpha$, which are homologues of human IL8 (Laterveer et al, 1995), and a decrease in antiinflammatory IL10 during the early phase of infection (Figure 4C). Inflammatory cell infiltration was observed in livers (Figure 4D) due to higher inflammation levels resulting from impaired bacterial clearance. Owing to unresolved infection, $A I D^{-1-}$ mice showed increased germinal centres (GCs) per $\mathrm{mm}^{2}$ of white pulp area at 9 and 14 d.p.i. as compared with the WT mice (Figure 4E), a sign of heightened immune activation, as was reported by Zaheen et al (2009). Survival was compromised in $A I D^{-/-}$mice (Figure $4 \mathrm{~F}$ ) due to unresolved infection and inflammation.

To confirm the protective role of natural IgG in vivo, we reconstituted $A I D^{-/-}$mice, $6 \mathrm{~h}$ prior to infection, with $2 \mathrm{mg}$ IgG (purified from uninfected WT mice serum and tested to be non-binding to $P$. aeruginosa). These mice showed an increase in serum IgG:ficolin complexes in the early phase of infection (Figure 5A, red box), indicating effective bacterial recognition; lower pro-inflammatory IL6 and TNF $\alpha$ and increased anti-inflammatory IL10 (Figure 5B); significantly lower tissue bacterial load (Figure 5C); no infiltration of inflammatory cells in the livers (Figure 5D); reduced GC area (Figure 5E) (GCs stained by anti-GL7 antibody); and lower GCs per $\mathrm{mm}^{2}$ of white pulp area (Figure $5 \mathrm{~F}$ ) compared with PBS-reconstituted controls. IgG is reported to interact with the B-cell inhibitory Fc receptor, $\gamma$ RIIB1 (D'Ambrosio et al, 1995; Zaheen et al, 2009). The administered IgG probably downregulated the GC B-cell survival, explaining the drop in GCs per white pulp area. Conclusively, we observed a significant improvement in the survival of IgGreconstituted $A I D^{-/-}$mice (Figure $5 \mathrm{G}$ ).

Next, we tested the bacterial recognition ability and protective role of natural IgG using representative members of natural IgGs, for example, anti-alpha gal IgG purified from uninfected human serum and IgG3 isolated from the serum of uninfected nude mice (Nu/J strain; which lack T cells and hence produce IgG3 in a TI manner) (Mink et al, 1980; Hayakawa and Hardy, 1988). Purified anti-alpha gal IgG by itself did not bind to the bacteria (Figure 6A) but was deposited dose dependently on ficolin pre-bound to the bacteria. The infection-inflammation condition significantly increased the recruitment of anti-alpha gal IgG onto PAMPassociated ficolin (Figure 6B). Likewise, IgG3 purified from nude mice serum was able to bind only in the presence of either ficolin or MBL, whereas depletion of both the lectins abrogated the bacterial recognition ability of IgG3 (Figure 6C). To prove the in vivo immune protection ability of IgG3, we reconstituted $A I D^{-/-}$mice with $0.2 \mathrm{mg}$ IgG3 (purified from nude mice serum), $6 \mathrm{~h}$ prior to infection. We observed a significant improvement in the survival of IgG3reconstituted mice as compared with the PBS-reconstituted control mice (Figure 6D), recapitulating the protective role of natural IgG during infection. Overall, these results emphasize that natural IgG is neither redundant nor quiescent; rather, it plays a crucial role in innate immune protection.

\section{IgG peptides targeting ficolin block IgG:ficolin interaction and make mice susceptible to infection}

Recently, we have identified IgG peptides (at the $\mathrm{CH} 2-\mathrm{CH} 3$ domain of the constant Fc region), which specifically interact with ficolin (Panda et al, manuscript under review). To provide in vivo evidence for the ficolin-aided role of natural IgG, WT mice were intravenously injected with the IgG peptides (ficolin binding or non-binding control), $2 \mathrm{~h}$ prior to infection with $P$. aeruginosa. We observed a substantial reduction in the formation of IgG:ficolin complex in the serum of mice injected with the ficolin-binding IgG peptides (Figure 7A), suggesting that these peptides competed with endogenous IgG for binding to bacteria-associated ficolin during infection, and specifically blocked the formation of IgG:ficolin immune complex. As a result, higher pro-inflammatory IL6 and TNF $\alpha$ and lower anti-inflammatory IL10 levels (Figure 7B) and higher tissue bacterial load (Figure 7C) were observed. Ultimately, the IgG peptide blockade of endogenous ficolin compromised the IgG:ficolinmediated immune protection (Figure 7D). These results confirm the physiological relevance of the ficolin-dependent action of natural IgG in innate immune defense.

Altogether, using an array of biochemical, cellular, and animal model experiments, we have demonstrated a novel, fundamentally conserved role of natural IgG in host-microbe interaction with immediate antimicrobial outcome, aided by lectins (ficolin and MBL). Figure 8 is a model representing the phenomenon of recruitment of natural IgG to the lectinbound pathogen leading to the effective clearance of the invading microbe through Fc $\gamma$ RI-mediated phagocytosis.

\section{Discussion}

Natural antibodies occur spontaneously in neonates and in 'antigen-free' healthy adults. They are likely to be products of the VDJ rearrangement and retain germline or near-germline configuration. Approximately $50 \%$ of total B cells in newborns and $20 \%$ in the peripheral circulation of healthy adults produce natural antibodies (Kantor and Herzenberg, 1993; Hardy and Hayakawa, 1994). Since natural antibodies do not possess specificity for any particular foreign antigen, they have been deemed incapable of launching an immediate effective attack on the microbe. The lack of a clearly defined function and mechanism of action of natural antibodies has hitherto been a longstanding unresolved scientific question.

We show for the first time that natural IgG, which contributes a major portion of natural antibodies, plays an essential and immediate protective role against infection. We demonstrated through in vitro studies that the natural 
A

6 h.p.i.
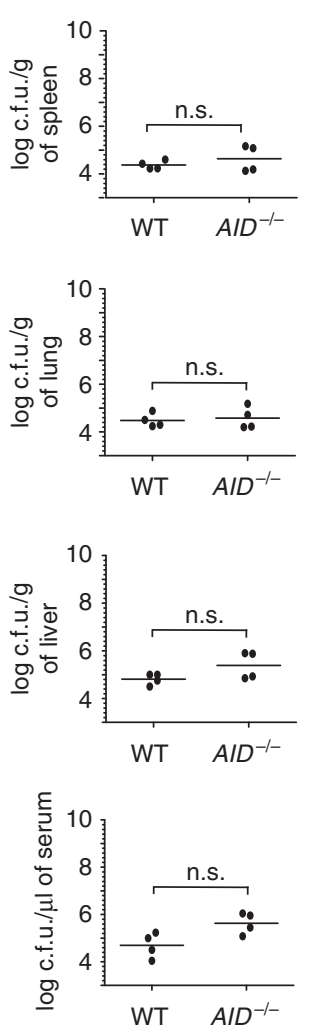

D
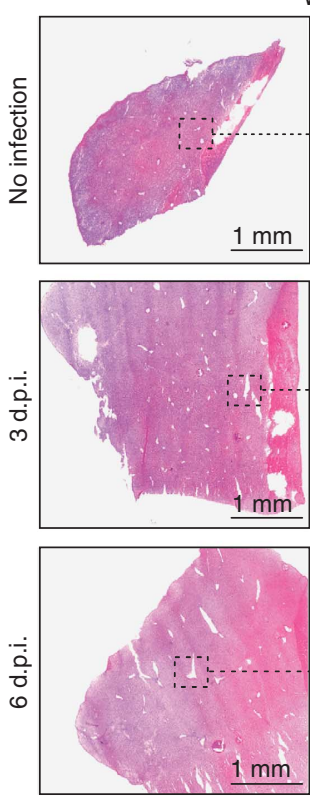

24 h.p.i.
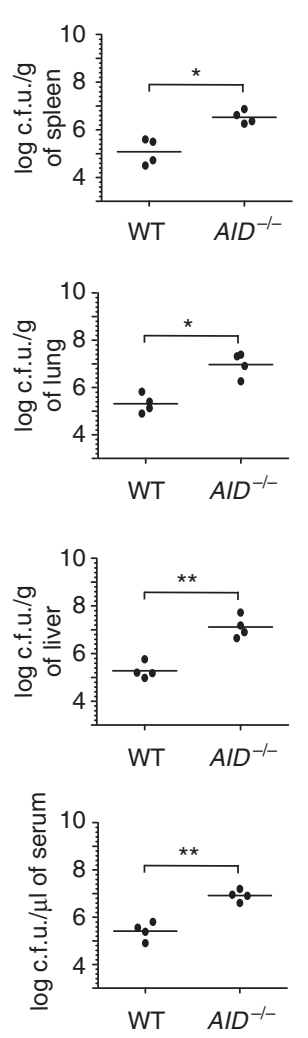

WT
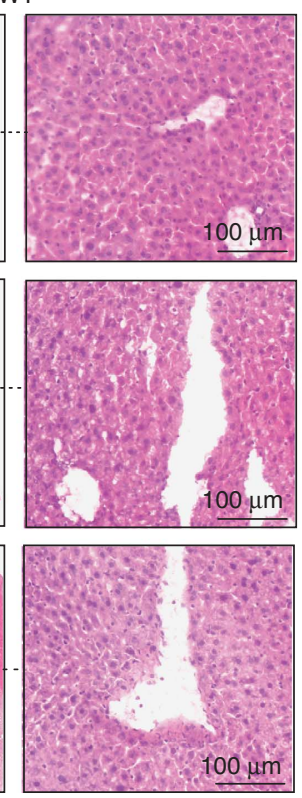
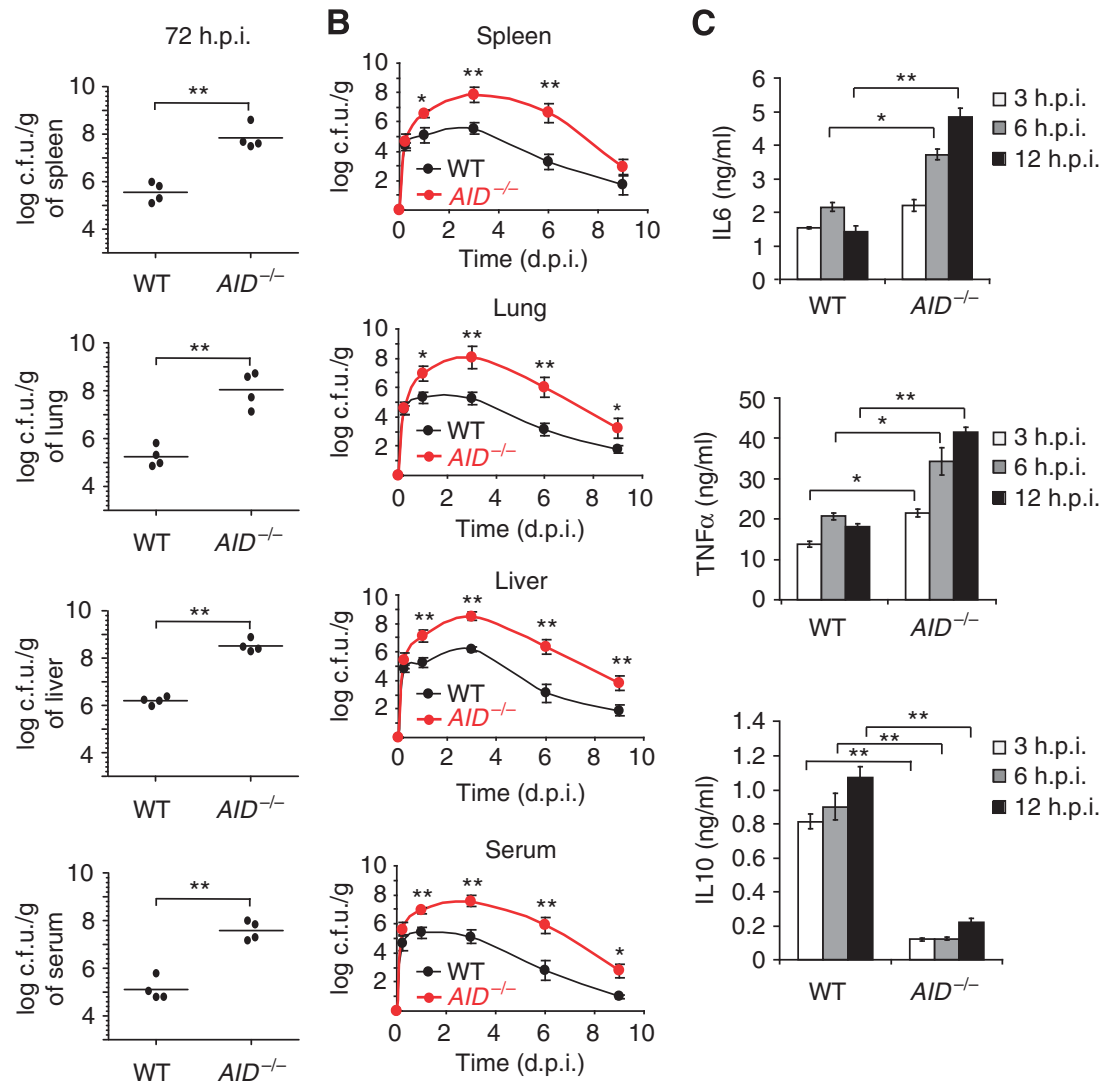

E
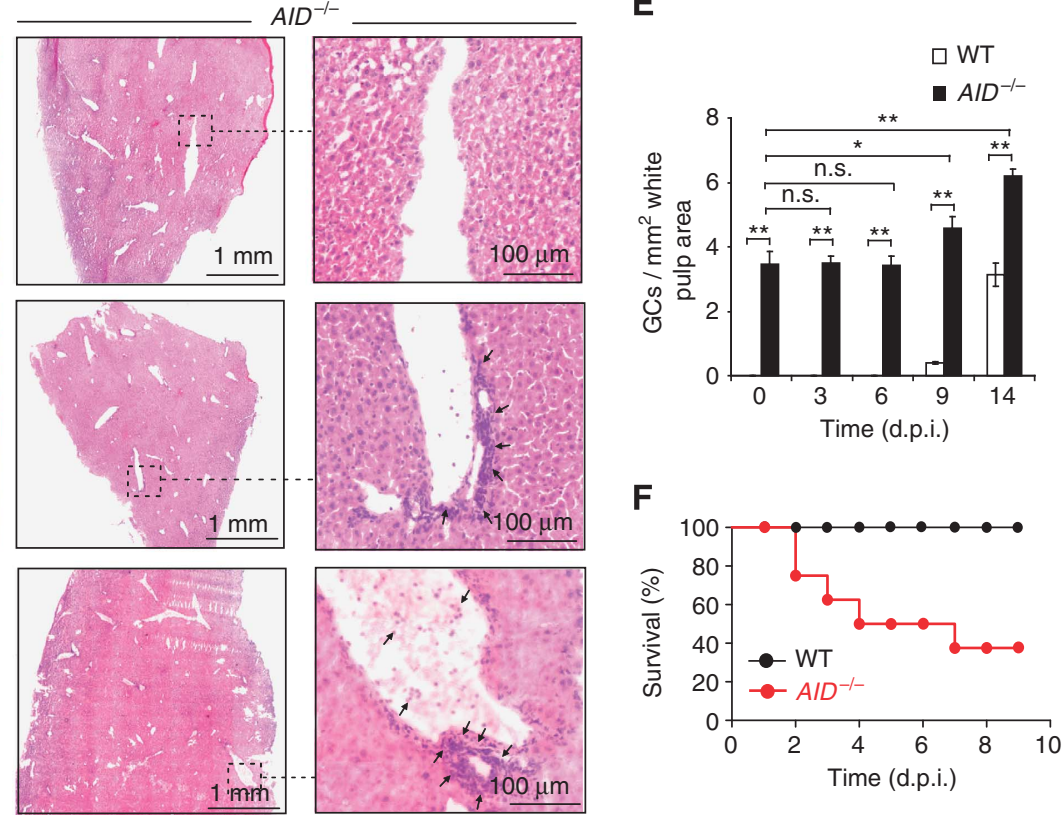

Figure $4 \mathrm{AID}^{-/-}$mice lacking natural IgG are susceptible to infection. (A-F) Both WT and $A I D^{-/-}$mice were infected with $10^{6}$ c.f.u. P. aeruginosa. (A) Log c.f.u. P. aeruginosa per gram spleen, lung, liver or per microlitre serum over $72 \mathrm{~h}$ post infection (h.p.i.) of WT and $A I D^{-\prime-}$ mice $(n=4$, each point represents an individual; horizontal lines indicate mean log c.f.u./g organ or c.f.u./ $\mu \mathrm{l} \mathrm{of} \mathrm{serum).} \mathrm{(B)} \mathrm{Log} \mathrm{c.f.u.}$ P. aeruginosa per gram tissue of WT and $A I D^{-1-}$ mice $(n=4)$ over 9 d.p.i. (C) ELISA to detect IL6, TNF $\alpha$, and IL10 levels in the pooled sera of WT and $A I D^{-1-}$ mice $\left(n=4\right.$ each) infected with $10^{6}$ c.f.u. P. aeruginosa, at 3, 6, and 12 h.p.i. Three replicates per sample were tested. ${ }^{*} P<0.05$; ${ }^{*} P<0.01$. (D) H\&E staining of liver sections from WT and $A I D^{-\prime}$-mice $(n=4)$. Whole tissue section images $(\times 2)$ and higher magnification $(\times 20)$ to highlight inflammatory cell infiltration (arrows). (E) Quantification of GCs per $\mathrm{mm}^{2}$ of white pulp area in spleen sections of WT and $A I D^{-1-}$ mice $(n=6)$. GCs were counted using bright-field microscopy and calculated by taking an average value from three H\&E sections per spleen/mouse. (F) Survival of infected WT or $A I D^{-/-}$mice $(n=8)$ monitored continuously for up to 9 d.p.i. ${ }^{*} P<0.05$; ${ }^{* *} P<0.01 ;$ n.s., not significant. 
A

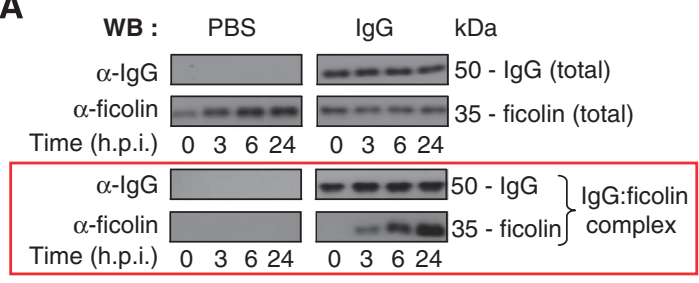

B $\square 3$ h.p.i. $\square 6$ h.p.i. $\square 3$ h.p.i. $\square 6$ h.p.i.
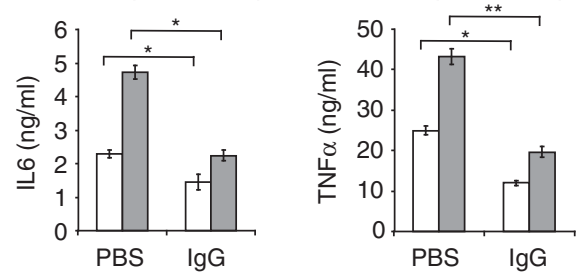

$\square 3$ h.p.i. $\quad \square 6$ h.p.i.

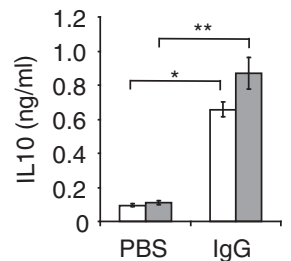

C
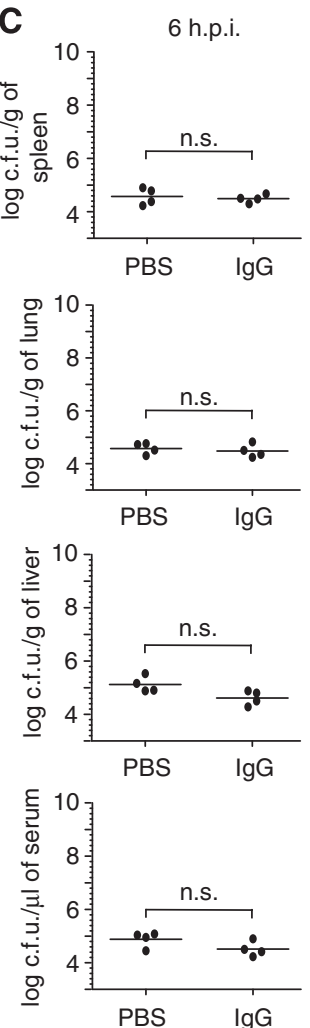

E

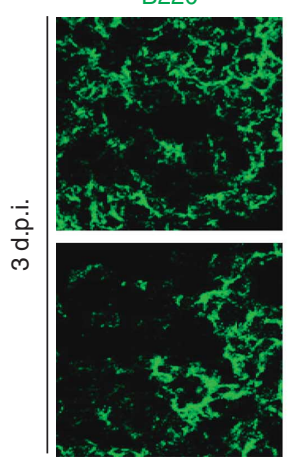

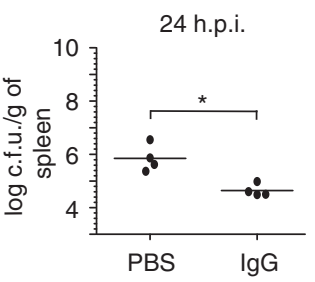
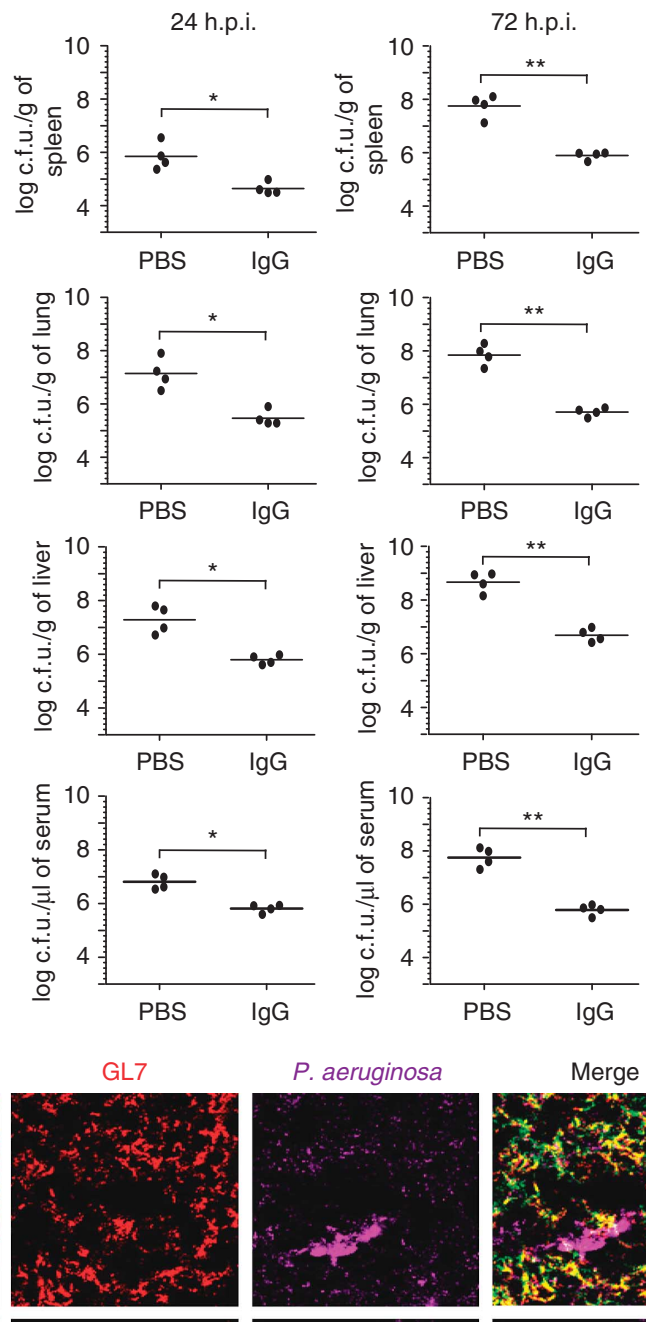

P. aeruginosa
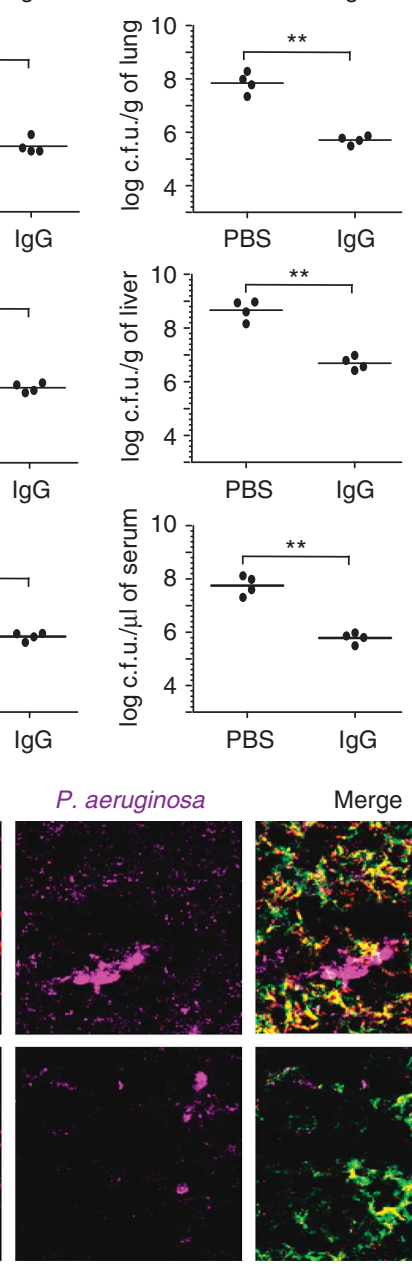

Merge

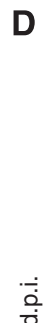
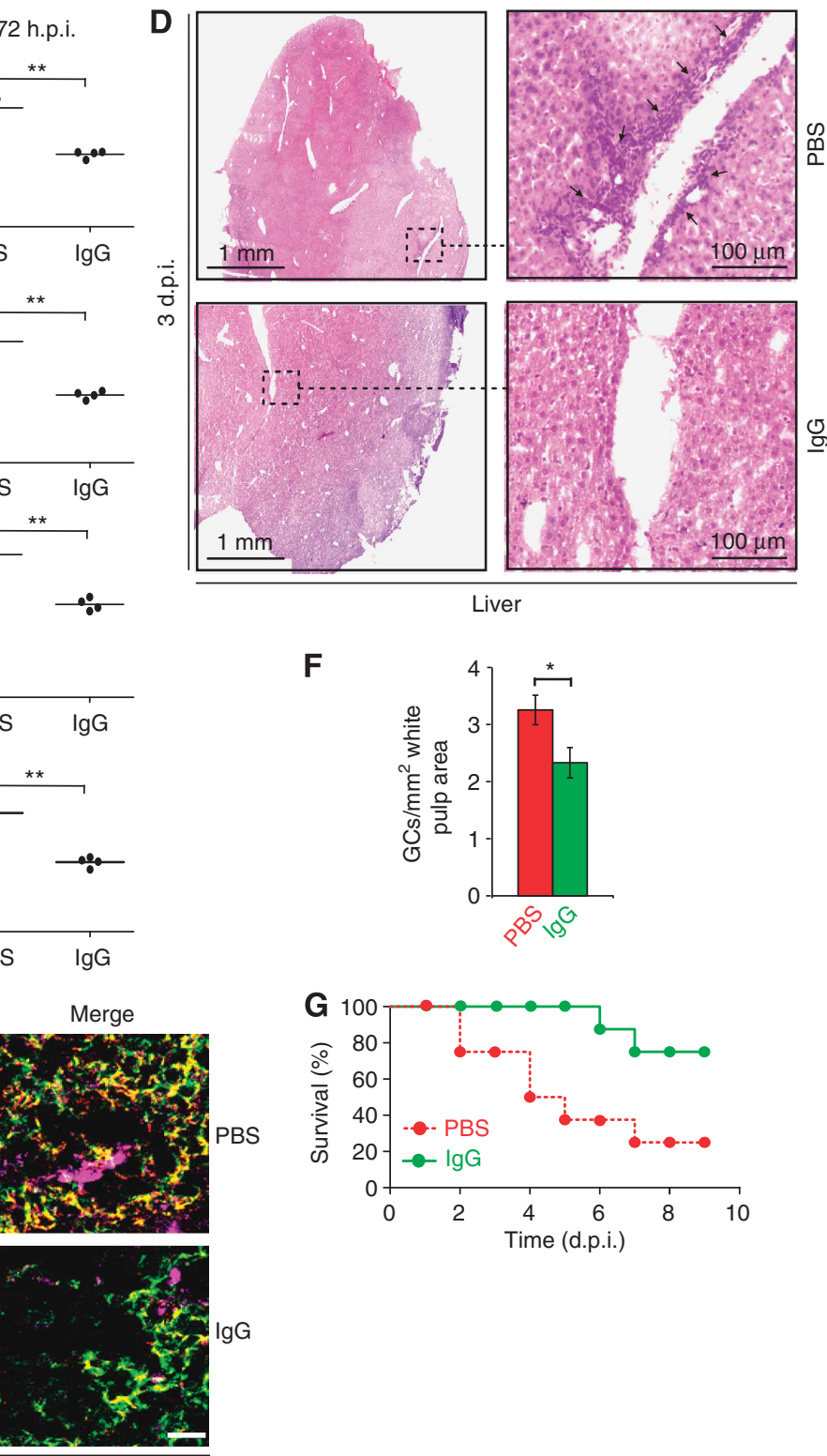

Spleen

Figure 5 Natural IgG confers innate immune protection to $A I D^{-/-}$mice. (A-G) Six hours prior to infection, $A I D^{-/-}$mice were administered intravenously with $2 \mathrm{mg}$ of IgG purified from uninfected pooled sera of WT mice $(n=8)$ (to reconstitute to normal IgG serum levels) or with PBS (control), and then infected with $10^{6}$ c.f.u. P. aeruginosa. (A) Immunoblot detects IgG (heavy chain), ficolin, and IgG:ficolin complex (pulled down by Protein G beads, red box) in pooled sera of $A I D^{-/}$- mice $(n=8)$. (B) ELISA to detect IL6, TNF $\alpha$, and IL10 levels in pooled sera of $A I D^{-/-}$mice $(n=4)$. Three replicates per sample were tested. (C) Log c.f.u. P. aeruginosa per gram of spleen, lung, liver and per microlitre of serum over 72 h.p.i. $(n=4$; each point represents an individual; horizontal lines indicate mean log c.f.u./g organ or c.f.u./ $\mu$ l serum). (D) Haematoxylin and Eosin staining of liver sections from $A I D^{-/-}$mice $(n=4)$. Whole tissue section images $(\times 2)$ and higher magnification $(\times 20)$ highlight inflammatory cell infiltration (arrows) in control mice reconstituted with PBS. (E) Detection of GC B cells in spleen sections $(n=6)$. Sections were stained with anti-B220 (B cell, green), anti-GL7 (germinal centre, red), and anti-P. aeruginosa (bacteria, purple). $\times 63$ objective; scale bar, $10 \mu \mathrm{m}$. (F) Quantification of GCs per $\mathrm{mm}^{2}$ white pulp area in spleen sections $(n=6)$ at 3 d.p.i. Same procedures were followed as described in Figure 4E. (G) Survival of infected PBS- or IgG-reconstituted $A I D^{-/}$mice $(n=8)$. The mice were monitored continuously for up to 9 d.p.i. ${ }^{*} P<0.05 ;{ }^{*} P<0.01$; n.s., not significant. Source data for this figure is available on the online supplementary information page. 
A

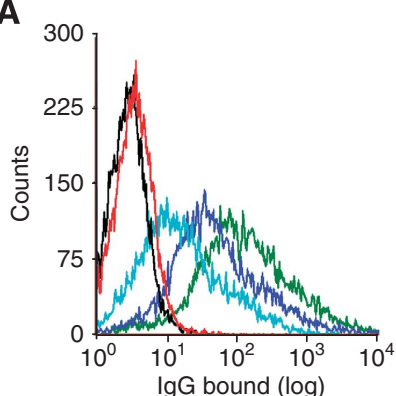

— IgG (purified anti-alpha gal lgG) - $\lg G+0.5 \mu \mathrm{g}$ ficolin - IgG $+1.0 \mu \mathrm{g}$ ficolin

- Ag-specific lgG (positive control)

$-2^{\circ} \mathrm{Ab}$ (negative control)

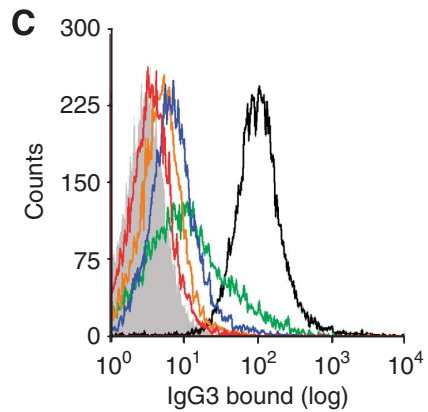

— Purified IgG3 alone

- Purified IgG3 + $\operatorname{lgG}^{-}$serum

- Purified lgG3 + $\operatorname{lgG}^{-}$ficolin ${ }^{-}$serum

- Purified lgG3 + $\operatorname{lgG}^{-} \mathrm{MBL}^{-}$serum

- Purified IgG3 + IgG ficolin ${ }^{-} \mathrm{MBL}^{-}$serum

$-2^{\circ} \mathrm{Ab}$ alone (negative control)

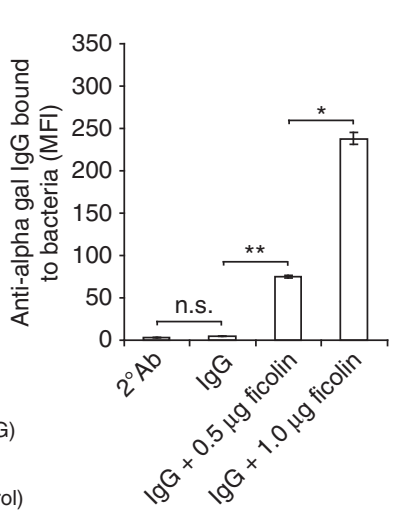

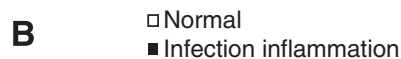

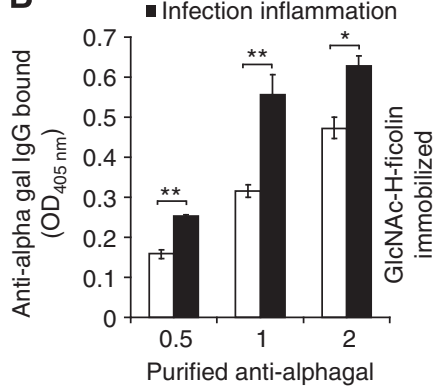

$\lg G(\mu \mathrm{g})$

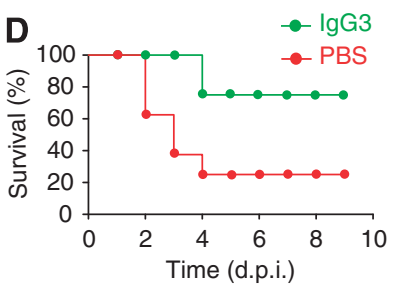

Figure 6 IgG3 (nude mice) and anti-alpha gal IgG (human) recognize bacteria with the aid of lectins and confer innate immune protection. (A) FACS quantification of the binding of purified anti-alpha gal IgG (from uninfected human serum) to $10^{6}$ c.f.u. P. aeruginosa. Bacteria were incubated with anti-alpha gal IgG alone or with 0.5 or $1 \mu \mathrm{g}$ H-ficolin. Bacteria opsonized with antigen-specific IgG and secondary antibody alone served as positive and negative controls, respectively. The graph compares the mean fluorescence intensity (MFI) of anti-alpha gal IgG bound to the bacteria incubated with IgG alone or IgG $+0.5 / 1.0 \mu \mathrm{g}$-ficolin. (B) ELISA to show binding of purified anti-alpha gal IgG to H-ficolin on immobilized GlcNAc, under normal and infection-inflammation conditions. (C) FACS analysis to detect binding of IgG3 purified from pooled sera of uninfected nude mice $(n=8)$ to $10^{6}$ c.f.u. P. aeruginosa. Bacteria were incubated with purified IgG3 alone (red) or with purified IgG3 + various depleted sera (annotated below figure). The IgG3 bound was probed with anti-mouse IgG3 and corresponding Alexa 488-conjugated secondary antibody. Bacteria incubated with $2^{\circ} \mathrm{Ab}$ alone served as the negative control (grey). The right panel is a plot depicting the $\%$ binding of purified IgG3 to the bacteria relative to IgG3 $+\operatorname{IgG}^{-}$serum values (all the values were subtracted from $2^{\circ} \mathrm{Ab}$ alone value). (D) The survival of $A I D^{-1-}$ mice $(n=8)$ infected with $10^{6}$ c.f.u. P. aeruginosa after intravenous administration with $0.2 \mathrm{mg}$ purified IgG3 (from uninfected nude mice) or with PBS (control). The mice were monitored continuously for up to 9 d.p.i. Three independent experiments with three replicates each were performed per sample/condition tested. ${ }^{*} P<0.05$; ${ }^{*} P<0.01$; n.s., not significant.

IgG recognizes a range of Gram-negative and Gram-positive bacteria through interaction with lectins bound on the surface of the invading bacteria. IgG then bridges the bacteria to the monocyte via Fc $\gamma$ RI for phagocytosis. The specificity and binding affinity of natural IgG:ficolin is tunable and enhanced by reduction in $\mathrm{pH}$ and calcium levels induced by infection inflammation.

The in vitro findings using human serum were further supported by studies using mice where we consistently found that the pool of natural IgG recognizes bacteria with the aid of lectins. Depletion of ficolin or MBL from the uninfected mice serum partially reduced IgG binding, whereas depletion of both ficolin and MBL completely abrogated the ability of natural IgG to recognize the pathogen, suggesting that natural IgG recruits multiple lectins to recognize bacteria.

The in vivo infection studies confirmed the physiological significance of natural IgG in antimicrobial defense.
In particular, we found that $A I D^{-/-}$mice (lacking IgG), which were susceptible to $P$. aeruginosa infection, were protected through reconstitution with purified non-antigen specific IgG in the early phase of infection, affirming the vital role of natural IgG in host-microbe interaction with a definitive innate immune defense response. The immune protection conferred by natural IgG was further confirmed by using purified representative natural IgGs such as human antialpha gal IgG and IgG3 from nude mice. Collectively, our findings have shown that although non-antigen specific, the natural IgG binds to pathogen-associated lectins to stage an immediate protection against a systemic infection in a complement C3-independent manner. This is crucial for the survival of individuals exposed to pathogens for the first time or in neonates still lacking antigen-specific antibodies, particularly for pathogens that evade complement killing mechanism. Future studies may include $F c \gamma R I^{-/-}$mice to provide additional support for the natural IgG-mediated 


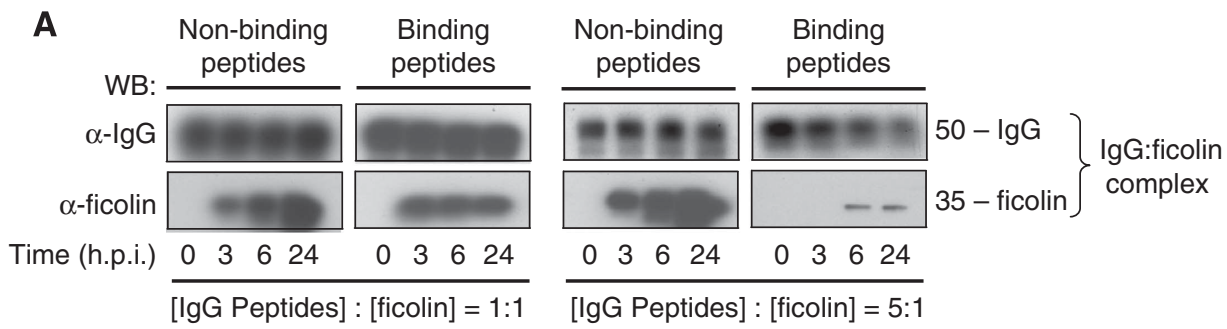

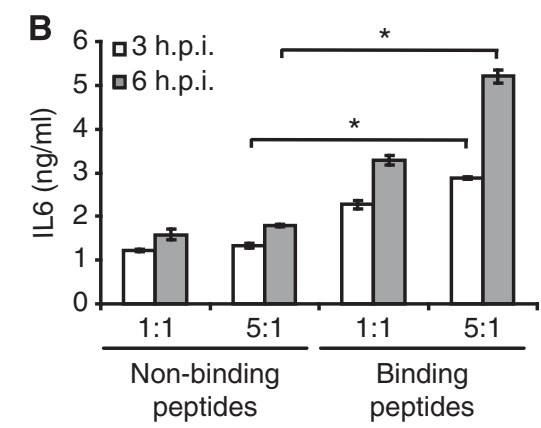

C
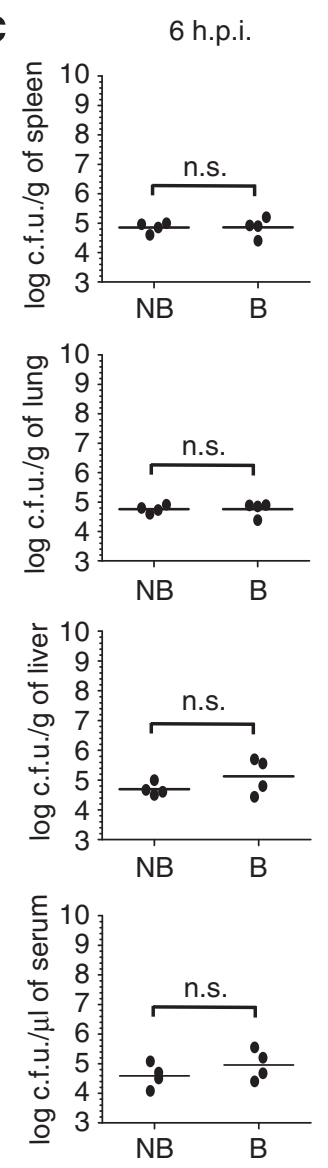

24 h.p.i.
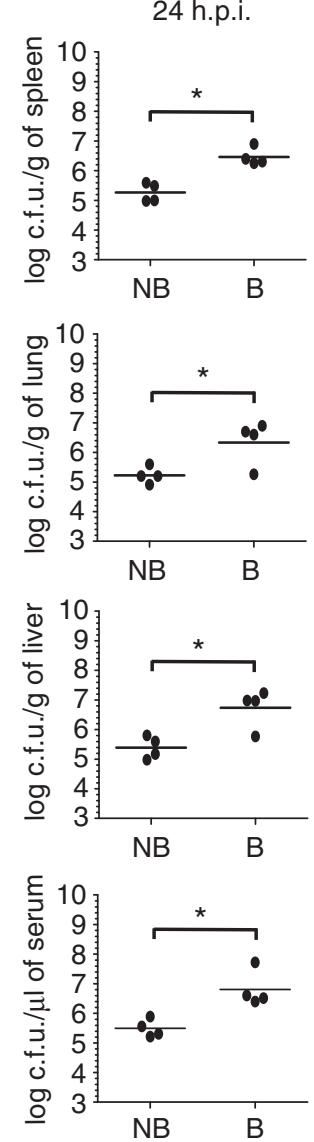
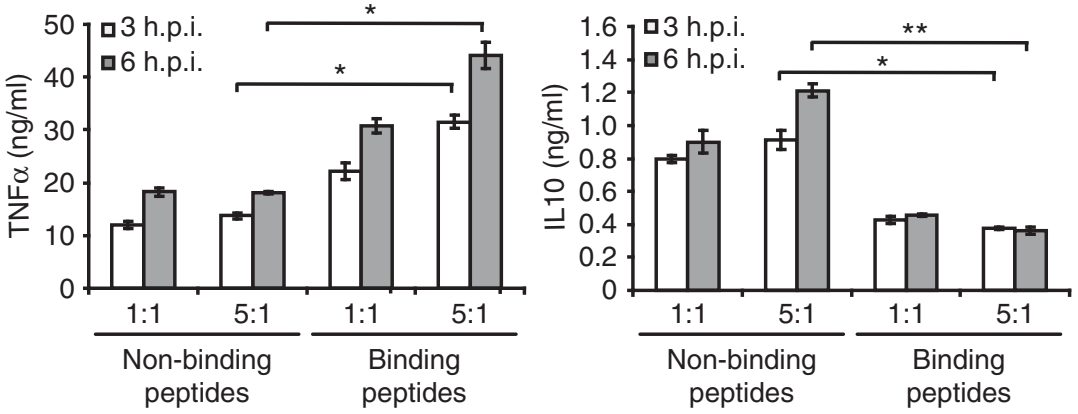

72 h.p.i. $\quad$ D
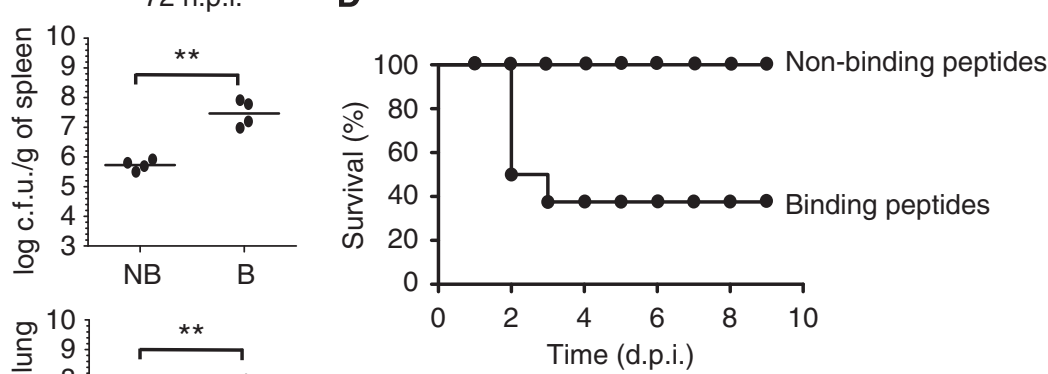
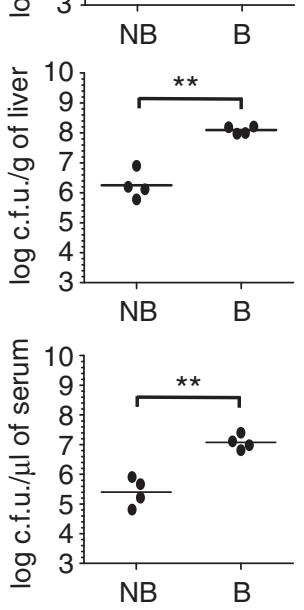

Figure 7 IgG peptides targeting ficolin block IgG:ficolin interaction and make mice susceptible to infection. (A-D) 2 h prior to infection, WT mice were administered intravenously with IgG peptides (binding or non-binding to ficolin) in (A, B) [peptides]:[ficolin] ratios of 1:1 or 5:1 based on the serum ficolin concentration or $(\mathbf{C}, \mathbf{D})$ ratio of $5: 1$. Following peptide treatment, the mice were infected with $10^{6}$ c.f.u. P. aeruginosa. (A) Immunoblot analysis of IgG:ficolin complex (pulled down by Protein $\mathrm{G}$ beads) in pooled sera of mice ( $n=3$ ) post-infection, over time course. (B) ELISA to detect pro-inflammatory IL6 and TNF $\alpha$ and anti-inflammatory IL10 levels in the pooled sera of mice $(n=4)$ at 3 and 6 h.p.i. Three replicates per sample were tested. (C) Log c.f.u. P. aeruginosa per gram of spleen, lung, liver and per millilitre of serum in mice over 72 h.p.i. $(n=4$; each point represents an individual mouse; horizontal lines indicate the mean log c.f.u./g organ or c.f.u./ml serum). (D) Survival curve of infected mice $(n=8)$. The mice were monitored continuously for up to 9 d.p.i. ${ }^{*} P<0.05$; ${ }^{*} P<0.01$; n.s., not significant. Source data for this figure is available on the online supplementary information page. 


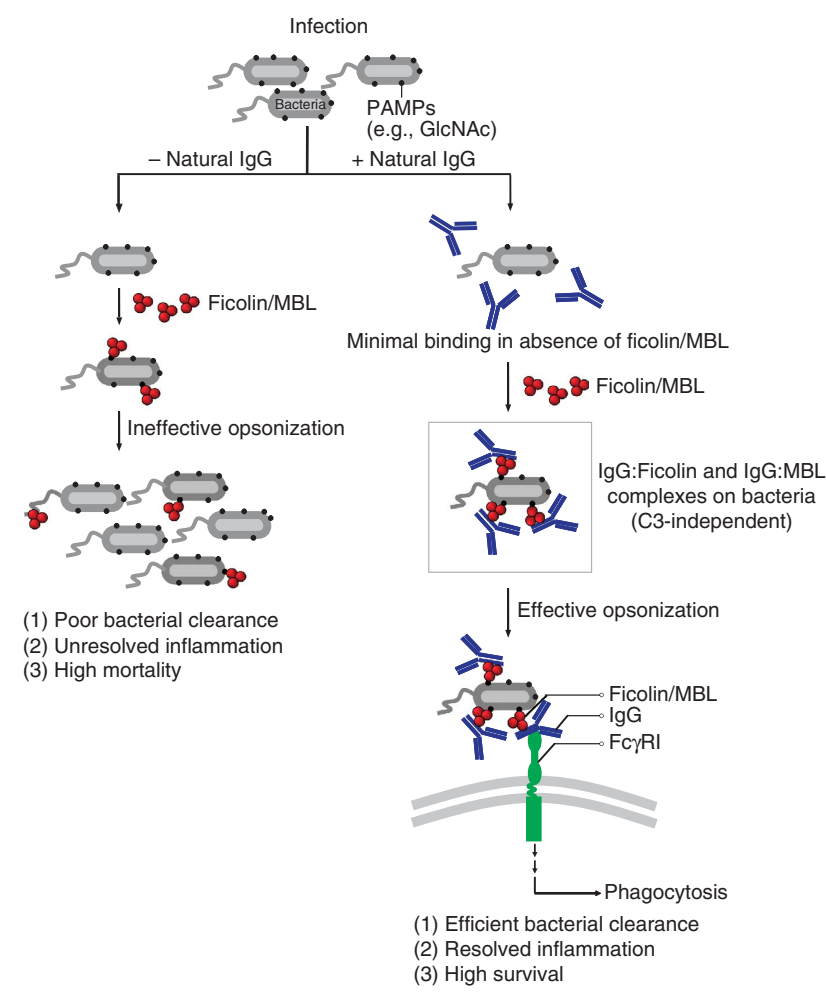

Figure 8 Natural IgG confers innate immune protection in collaboration with lectins. Proposed model to illustrate the novel mechanism of bacterial recognition and phagocytosis through the assembly of lectin (such as ficolin and MBL) (red), natural IgG (blue) and Fc $\gamma \mathrm{RI}$ (green) on monocytes, [bacteria-lectin:IgG:Fc $\gamma \mathrm{RI}-$ monocytes]. Natural IgG acts as a crucial bridge between lectin opsonized bacteria and Fc $\gamma$ RI, leading to direct and rapid phagocytosis of the pathogen. The left side of the model illustrates that in $A I D^{-/-}$mice (- natural IgG), the bacterial load remained high (supported by Figure 4A and B), with higher pro-inflammatory cytokine levels in the early phase of infection (supported by Figure 4C). This probably compromised the survival of the mice (supported by Figure 4F). The right side of the model illustrates that natural IgG collaborates with lectins bound on bacteria in a C3independent manner (supported by Supplementary Figure S6) and affected phagocytosis through Fc $\gamma$ RI on monocytes. Reconstitution of $A I D^{-1-}$ mice with natural IgG ( + natural IgG) conferred early innate immune protection against infection compared with PBSreconstituted controls (supported by Figure 5).

bacterial phagocytosis in vivo. However, the use of ficolin ${ }^{-/-}$ or $M B L^{-/-}$mice for further studies may be unfavorable since our findings showed that natural IgG engages both serum lectins, indicating that the lack of ficolin may likely to be compensated by MBL and vice versa. Nevertheless, we have shown that IgG peptides targeting endogenous ficolin blocked IgG:ficolin complex formation in mice, which compromised the protective effect of natural IgG. This result supports the significance of ficolin in aiding natural IgG activity in vivo.

Besides clearing pathogens, natural antibodies, particularly the well-studied natural IgM, also play a crucial role in various homeostatic mechanisms (Senaldi et al, 1988; Ogden et al, 2005; Chen et al, 2009; Lewis et al, 2009; Ehrenstein and Notley, 2010). Although natural IgG has been shown to recognize a variety of self-antigens, and is a speculated biomarker for Alzheimer's and Parkinson's diseases (Nagele et al, 2013), its contribution in controlling homeostatic conditions is still unclear. It will be interesting to explore the potential physiological/homeostatic function(s) of natural IgG in biological processes, for example, B-cell development and survival, modulation of self-antigen environment, prevention of auto-immune diseases, and regulation of cellular turnover. Another interesting aspect that remains to be explored is the possible role of natural antibodies in mucosal immunity since natural antibodies and ficolins are also abundant in the intestinal mucosa (Kroese et al, 1993; Akaiwa et al, 1999). Recent studies have highlighted the role of ficolins in preventing necrotizing enterocolitis in newborns (Schlapbach et al, 2011). We postulate that natural IgA may elicit frontline defense in mucosal immunity via a similar / related mechanism of action as reported here.

Our findings have opened new avenues on the potential for combating pathogen immune evasion by broadly enhancing natural resistance through natural antibodies. Overall, our discovery that natural IgG is not quiescent, but actively interacts with microbes associated with lectins, will alter our perception of the fundamental role of natural antibodies in the recognition of pathogens and provocation of innate immune defense. The natural IgG in combination with lectins could be developed as a prophylactic drug, tunable to reduced $\mathrm{pH}$ and calcium levels, to combat bacterial infections.

\section{Materials and methods}

\section{Mice}

Six- to eight-week-old C57BL/6 mice were inbred under 'specific pathogen free' conditions at the NUS CARE facility. $A I D^{-/-}$and $\mathrm{C}^{-1-}$ mice (B6 background) were also maintained under similar conditions. Gender- and age-matched mice were used in the experiments. Systemic infection of the mice was performed intravenously through the tail vein. All experiments were carried out in compliance with institutional guidelines and approved by the Institutional Animal Care and Use Committee (IACUC Protocol Ref: 049/11, BR14/11).

\section{Human primary monocytes and cell cultures}

Human primary monocytes were purified from the buffy coat by Ficoll-Hypaque (Sigma-Aldrich) gradient centrifugation followed by magnetic cell sorting using the EasySep Monocyte Isolation Kit (Stem cell Technologies) according to the manufacturer's instructions (Cao et al, 2005). The primary monocytes were cultured at $37^{\circ} \mathrm{C}$ in RPMI-1640 (Invitrogen) supplemented with $10 \%(\mathrm{v} / \mathrm{v}) \mathrm{FBS}$ (Invitrogen), $100 \mathrm{IU} / \mathrm{ml}$ penicillin, and $100 \mu \mathrm{g} / \mathrm{ml}$ streptomycin (Invitrogen). HEK293T cells were cultured in DMEM (Invitrogen) supplemented with $10 \%$ FBS, $100 \mathrm{IU} / \mathrm{ml}$ penicillin, and $100 \mu \mathrm{g} / \mathrm{ml}$ streptomycin.

\section{Simulation of 'normal' and 'infection-inflammation' conditions in vitro}

Infection-inflammation condition has been reported to induce acidosis leading to a drop in pH from 7.4 to 6.5 (Martinez et al, 2006). The calcium level in the tissue microenvironment of infected patients has also been shown to drop to $\leqslant 2 \mathrm{mM}$ compared with 2.2-2.6 mM in healthy tissues (TranVan Nhieu et al, 2004; Prince et al, 2006; Eichstaedt et al, 2009). Hence, for our in vitro studies, we simulated 'normal condition' (TBS buffer containing $25 \mathrm{mM}$ Tris, $145 \mathrm{mM} \mathrm{NaCl}, \mathrm{pH} 7.4$, and $2.5 \mathrm{mM} \mathrm{CaCl}$ ) and 'infectioninflammation condition' (MBS buffer containing $25 \mathrm{mM}$ MES, $145 \mathrm{mM} \mathrm{NaCl}, \mathrm{pH} 6.5$, and $2 \mathrm{mM} \mathrm{CaCl} 2$ ) using specific buffers, a method commonly employed by others (Miyazawa and Inoue, 1990; $\mathrm{Gu}$ and Lee, 2006; Zhang et al, 2009).

\section{Analyses of protein binding and phagocytosis by flow cytometry}

Cultures of $P$. aeruginosa PAO1, E. coli Top 10, S. aureus, or $S$. epidermidis were prepared for flow cytometry as previously described (Zhang et al, 2009). To assess the binding of purified 
IgG to bacteria, the microbes were incubated with (i) purified IgG/ anti-alpha gal IgG (from uninfected human serum-see purification details in Supplementary data) with or without ficolin and (ii) purified IgG (from uninfected WT mice serum)/IgG3 (from uninfected nude mice serum) with or without serum depleted of IgG or serum depleted of both IgG and ficolin or MBL or both, for $2 \mathrm{~h}$ at room temperature. Bacteria were washed to remove unbound proteins and stained with primary anti-human IgG (1:500) or antimouse IgG (1:500) or anti-mouse IgG3 (1:300), followed by staining with corresponding Alexa 488-conjugated secondary antibody (1:500) (Invitrogen). Bacteria incubated with specific primary antibody and stained with Alexa 488-conjugated secondary antibody (1:500) served as a positive control. Flow cytometry was performed using Dako Cyan Cytomation LX (Becton Dickinson).

GFP-tagged $P$. aeruginosa were cultured in LB broth containing $25 \mu \mathrm{g} / \mathrm{ml}$ kanamycin selection medium, in a similar manner described by Zhang et al (2009). For phagocytosis assay, the GFP bacteria were incubated with ficolin or IgG or both the proteins at room temperature for $2 \mathrm{~h}$ in $500 \mu \mathrm{l}$ of 'normal' or 'infectioninflammation' buffers to generate opsonized GFP bacteria (1:10 diluted serum served as a positive control and HSA with IgG served as a negative control). The opsonized GFP bacteria were incubated with human monocytes in a ratio of $10: 1$ at $37^{\circ} \mathrm{C}$ for up to $60 \mathrm{~min}$. Phagocytosis was stopped by adding $1 \mathrm{ml}$ ice-cold PBS. Following incubation, the monocytes were collected, washed thrice with TBS or MBS buffers, and fixed with $4 \%$ paraformaldehyde. The extent of phagocytosis was assayed by counting the percentage of monocytes with GFP fluorescence (a measure of the degree of phagocytosis), using flow cytometry.

\section{Real-time biointeraction analysis}

BIAcore 2000 instrument (BIAcore $\mathrm{AB}$ ) was used to demonstrate the real-time biointeraction between the proteins. CM5 chip was immobilized with $10 \mu \mathrm{g} / \mathrm{ml}$ GlcNAc-BSA (Dextra Labs, UK) in $10 \mathrm{mM}$ sodium acetate, pH 4.0 using amine-coupling chemistry, according to the manufacturer's specifications. Next, ficolin ( $200 \mathrm{nM}$ full-length or FBG domain) in running buffer was injected to bind to the GlcNAc-immobilized chip for association and dissociation times specified in the figure legends. To characterize the binding of IgG to ficolin, separate injections of increasing concentrations of IgG were made under similar conditions. The flow rate was maintained throughout at $30 \mu \mathrm{l} / \mathrm{min}$. Regeneration to remove the bound proteins after one cycle was affected by injecting $15 \mu \mathrm{l}$ of $0.1 \mathrm{M} \mathrm{NaOH}$.

To study the interaction between ficolin and IgG bound to Fc $\gamma$ RI, we immobilized purified Fc $\gamma$ RI on a CM5 chip using amine-coupling chemistry. In all, $50 \mathrm{nM}$ IgG in running buffer was injected over Fc $\gamma$ RI-immobilized chip for association and dissociation time as specified in the figure legends, followed by separate injections of increasing concentrations of ficolin FBG. Injection of HSA instead of ficolin FBG served as the negative control. The running buffer for 'normal condition' was TBS buffer $(25 \mathrm{mM}$ Tris, $145 \mathrm{mM} \mathrm{NaCl}, \mathrm{pH}$ 7.4 , and $2.5 \mathrm{mM} \mathrm{CaCl}_{2}$ ) and for 'infection-inflammation condition' was MBS buffer (25 mM MES, $145 \mathrm{mM} \mathrm{NaCl}, \mathrm{pH} 6.5$, and $2 \mathrm{mM}$ $\mathrm{CaCl}_{2}$ ). The BIA evaluation 3.2 software was used to calculate the $K_{\mathrm{D}}$ using a 1:1 Langmuir binding model. All binding curves (black) were overlaid with the fit of $1: 1$ binding model (red). All the SPR curves used in $K_{\mathrm{D}}$ calculation were normalized against buffer alone controls. The resonance unit difference before and after injection represents the protein-protein interaction. The plots shown are representative of three independent experiments.

\section{ELISA for measurement of protein:protein binding, human IL8, and mouse serum IgG}

ELISA was performed as described previously (Zhang et al, 2009), to test the interaction between purified IgG/anti-alpha gal IgG and ficolin (full-length, FBG and collagen-like domains) or specific IgG isotypes (IgG1, IgG2, and IgG3). Briefly, $1 \mu$ g of GlcNAc-BSA was immobilized in each well of a 96-well Maxisorp ${ }^{\mathrm{TM}}$ plate (NUNC, Denmark), followed by $0.8 \mu \mathrm{g}$ of ficolin. Then, increasing doses of purified IgG/anti-alpha gal IgG or uninfected human serum diluted in buffers was added and incubated at $37^{\circ} \mathrm{C}$ for $2 \mathrm{~h}$. After washing, the wells repeatedly to remove unbound proteins, bound IgG/antialpha gal IgG, or specific IgG isotypes were detected with the primary anti-human IgG $(1: 3000)$ followed by respective HRPconjugated secondary antibody (1:3000). After adding an ABTS substrate (Roche Diagnostics, Germany), the $\mathrm{OD}_{405 \mathrm{~nm}}$ was read. Wells incubated with HSA on immobilized ficolin served as negative controls, unless otherwise stated.

For TNF $\alpha$, IL6, IL8, and IL10 measurement, the primary human monocytes were plated at $0.5 \times 10^{6} \mathrm{cells} / \mathrm{ml} /$ well into 24 -well plates. The cell culture medium (advanced RPMI) was renewed before addition of $10 \mathrm{mM} \mathrm{GlcNAc}$, in the absence or presence of ficolin and IgG, to replicate wells for $24 \mathrm{~h}$, and the medium was collected and clarified by centrifugation at $1000 \mathrm{~g}$ for $5 \mathrm{~min}$ at $4{ }^{\circ} \mathrm{C}$. To test the functional significance of Fc $\gamma$ RI in IgG:ficolin complex mediated immune response, Fc $\gamma$ RI-knockdown cells were treated under similar conditions. Cell culture supernatant was collected $24 \mathrm{~h}$ after stimulation and diluted 100 times before ELISA. Secreted cytokines were quantified with the respective OptEIA human cytokine ELISA (BD Biosciences) immunoassay kit according to the manufacturer's instructions. The $\mathrm{OD}_{405 \mathrm{~nm}}$ was read.

For mouse serum IgG measurement, blood was collected from mice by cardiac puncture, allowed to clot, spun down at $1000 \mathrm{~g}$ for 5 min and serum was collected. IgG concentration was determined in the pooled serum by using commercial ELISA kits (Roche) according to the manufacturer's instructions.

\section{Immunofluorescence staining}

For cellular co-localization analysis, human primary monocytes were plated onto coverslips in 12-well plates (Sterilin, UK) at a density of $0.5 \times 10^{6}$ cells $/ \mathrm{ml}$. The cells were then incubated with the proteins for $20 \mathrm{~min}$ at $37^{\circ} \mathrm{C}$, after which they were washed thrice with PBS and fixed using $4 \%$ paraformaldehyde for $15 \mathrm{~min}$ at room temperature. For mouse spleen immunofluorescence staining, the frozen sections ( $5 \mu \mathrm{m}$ thick) were mounted onto Superfrost* Plus slides (Fisher Scientific) and fixed using $4 \%$ paraformaldehyde for $15 \mathrm{~min}$ at room temperature. Non-specific staining between the primary antibodies and the cells or tissue was blocked by incubating in blocking buffer ( $3 \% \mathrm{BSA}$ in PBS) for $30 \mathrm{~min}$ at room temperature. Then, the samples or sections were incubated with the respective primary and secondary antibodies diluted in incubation buffer (3\% BSA in PBS containing 0.05\% Tween-20) for $60 \mathrm{~min}$ at room temperature and washed thrice with PBS containing $0.05 \%$ Tween-20. To stain the nucleus, a drop of Prolong Gold antifade reagent with DAPI (Invitrogen) was added in the mounting media. Imaging was performed using an LSM META 510 confocal microscope (Carl Zeiss) under a $\times 63 / \times 100$ oil objective.

\section{Cytokine levels in the mouse serum and bacterial counts in the tissues}

Mice were infected intravenously through tail vein injection with $10^{6}$ or $10^{7}$ c.f.u. P. aeruginosa for the indicated time. Blood was collected from uninfected or infected mice by cardiac puncture, allowed to clot, spun down at $1000 \mathrm{~g}$ for $5 \mathrm{~min}$ and serum was collected. The concentrations of IL6, TNF $\alpha$, and IL10 were determined in the pooled serum by using commercial ELISA kits (BD Biosciences) according to the manufacturer's instructions. For bacterial counts in the tissues, spleen, liver, and lung were collected and resuspended in PBS, excised into small pieces, mixed with $5 \mathrm{mg} / \mathrm{ml}$ of saponin, and incubated for $10 \mathrm{~min}$ at $37^{\circ} \mathrm{C}$ to release the internalized bacteria. The samples were centrifuged at $1200 \mathrm{~g}$ for $10 \mathrm{~min}$, resuspended in PBS, serially diluted, and plated on LB agar plates. Viable bacterial counts were scored after overnight incubation at $37^{\circ} \mathrm{C}$.

\section{Statistical analysis}

For all experiments, three replicates were performed per sample/ condition tested. Data are presented as mean \pm s.e.m. of three independent experiments. Differences between averages were analysed by two-tailed Student's $t$-test. Significance was set at a $P$-value of $<0.05$. ${ }^{*} P<0.05 ;{ }^{*} P<0.01$; n.s. not significant. Differences in survival were analysed by the log-rank test.

\section{Supplementary data}

Supplementary data are available at The EMBO Journal Online (http://www.embojournal.org).

\section{Acknowledgements}

We thank the Ministry of Education (Tier 2 grant: T208B3109) and A*STAR BMRC (Grant: 10/1/21/19/658) for supporting this 
research. Saswati Panda is a graduate research scholar of the National University of Singapore. Jing Zhang was an NGS scholar. We are grateful to Dr Garnett Kelsoe (Duke University, USA) for the $A I D^{-\prime-}$ mice, obtained with kind permission from Dr Tasuku Honjo (Kyoto University, Japan) and Dr Sivasankar Baalasubramanian (Singapore Institute for Clinical Sciences) for providing $\mathrm{C}^{-/-}$mice (Jackson Laboratories) and serum. We thank Dr Enoka Bandularatne (Comparative Medicine, National University of Singapore) for veterinary advice and Dr Ming Teh (Department of Pathology, National University Hospital, Singapore) for expert guidance on assessing the germinal centres per white pulp area in spleens of mice. We thank Dr Sae Kyung Lee and Dr Yong Zhu for proofreading the manuscript and Mazlina Banu for providing technical help.

\section{References}

Akaiwa M, Yae Y, Sugimoto R, Suzuki SO, Iwaki T, Izuhara K, Hamasaki N (1999) Hakata antigen, a new member of the ficolin/ opsonin p35 family, is a novel human lectin secreted into bronchus/alveolus and bile. J Histochem Cytochem 47: 777-786

Avrameas S (1991) Natural autoantibodies: from 'horror autotoxicus' to 'gnothi seauton'. Immunol Today 12: 154-159

Baranov D, Neligan P (2007) Trauma and aggressive homeostasis management. Anesthesiol Clin 25: 49-63 viii

Bessman AN, Page J, Thomas LJ (1989) In vivo pH of induced softtissue abscesses in diabetic and nondiabetic mice. Diabetes 38: 659-662

Boyden SV (1966) Natural antibodies and the immune response. Adv Immunol 5: 1-28

Burton DR, Jefferis R, Partridge LJ, Woof JM (1988) Molecular recognition of antibody (IgG) by cellular Fc receptor (FcRI). Mol Immunol 25: 1175-1181

Cao W, Lee SH, Lu J (2005) CD83 is preformed inside monocytes, macrophages and dendritic cells, but it is only stably expressed on activated dendritic cells. Biochem J 385: 85-93

Chen Y, Khanna S, Goodyear CS, Park YB, Raz E, Thiel S, Gronwall C, Vas J, Boyle DL, Corr M, Kono DH, Silverman GJ (2009) Regulation of dendritic cells and macrophages by an anti-apoptotic cell natural antibody that suppresses TLR responses and inhibits inflammatory arthritis. J Immunol 183: 1346-1359

D’Ambrosio D, Hippen KL, Minskoff SA, Mellman I, Pani G, Siminovitch KA, Cambier JC (1995) Recruitment and activation of PTP1C in negative regulation of antigen receptor signaling by Fc gamma RIIB1. Science 268: 293-297

Dempsey PW, Vaidya SA, Cheng G (2003) The art of war: Innate and adaptive immune responses. Cell Mol Life Sci 60: 2604-2621

Ehrenstein MR, Notley CA (2010) The importance of natural IgM: scavenger, protector and regulator. Nat Rev Immunol 10: 778-786

Eichstaedt S, Gabler K, Below S, Muller C, Kohler C, Engelmann S, Hildebrandt P, Volker U, Hecker M, Hildebrandt JP (2009) Effects of Staphylococcus aureus-hemolysin A on calcium signalling in immortalized human airway epithelial cells. Cell Calcium 45: 165-176

Graille M, Stura EA, Corper AL, Sutton BJ, Taussig MJ, Charbonnier JB, Silverman GJ (2000) Crystal structure of a Staphylococcus aureus protein A domain complexed with the Fab fragment of a human IgM antibody: structural basis for recognition of B-cell receptors and superantigen activity. Proc Natl Acad Sci USA 97: 5399-5404

Gu Q, Lee LY (2006) Characterization of acid signaling in rat vagal pulmonary sensory neurons. Am J Physiol Lung Cell Mol Physiol 291: L58-L65

Hardy RR, Hayakawa K (1994) CD5 B cells, a fetal B cell lineage. Adv Immunol 55: 297-339

Hayakawa K, Hardy RR (1988) Normal, autoimmune, and malignant CD5 + B cells: the Ly-1 B lineage? Annu Rev Immunol 6: 197-218

Indik ZK, Park JG, Hunter S, Schreiber AD (1995) The molecular dissection of Fc gamma receptor mediated phagocytosis. Blood 86: 4389-4399

Kantor AB, Herzenberg LA (1993) Origin of murine B cell lineages. Annu Rev Immunol 11: 501-538

Kroese FG, Ammerlaan WA, Kantor AB (1993) Evidence that intestinal IgA plasma cells in mu, kappa transgenic mice are derived from B-1 (Ly-1 B) cells. Int Immunol 5: 1317-1327
Author contributions: SP designed, performed, and analysed the experiments in this study with intellectual input from JLD. JZ provided advice in designing in vitro experiments. NST provided advice and intellectual input in various aspects of the work. $\mathrm{BH}$ provided the bacterial strains and intellectual input. JLD provided overall coordination with respect to conception, design, and supervision of the study. SP and JLD wrote the manuscript with comments from co-authors.

\section{Conflict of interest}

The authors declare that they have no conflict of interest.

Kube D, Sontich U, Fletcher D, Davis PB (2001) Proinflammatory cytokine responses to $\mathrm{P}$. aeruginosa infection in human airway epithelial cell lines. Am J Physiol Lung Cell Mol Physiol 280: L493-L502

Laterveer L, Lindley IJ, Hamilton MS, Willemze R, Fibbe WE (1995) Interleukin-8 induces rapid mobilization of hematopoietic stem cells with radioprotective capacity and long-term myelolymphoid repopulating ability. Blood 85: 2269-2275

Lewis MJ, Malik TH, Ehrenstein MR, Boyle JJ, Botto M, Haskard DO (2009) Immunoglobulin $\mathrm{M}$ is required for protection against atherosclerosis in low-density lipoprotein receptor-deficient mice. Circulation 120: 417-426

Liu B, Zhang J, Tan PY, Hsu D, Blom AM, Leong B, Sethi S, Ho B, Ding JL, Thiagarajan PS (2011) A computational and experimental study of the regulatory mechanisms of the complement system. PLoS Comput Biol 7: e1001059

Ma YJ, Doni A, Hummelshoj T, Honore C, Bastone A, Mantovani A, Thielens NM, Garred P (2009) Synergy between ficolin-2 and pentraxin 3 boosts innate immune recognition and complement deposition. J Biol Chem 284: 28263-28275

Marsh CB, Anderson CL, Lowe MP, Wewers MD (1996) Monocyte IL-8 release is induced by two independent Fc gamma Rmediated pathways. J Immunol 157: 2632-2637

Martinez D, Vermeulen M, Trevani A, Ceballos A, Sabatte J, Gamberale R, Alvarez ME, Salamone G, Tanos T, Coso OA, Geffner J (2006) Extracellular acidosis induces neutrophil activation by a mechanism dependent on activation of phosphatidylinositol 3-kinase/Akt and ERK pathways. J Immunol 176: 1163-1171

Matsushita M, Endo Y, Taira S, Sato Y, Fujita T, Ichikawa N, Nakata M, Mizuochi T (1996) A novel human serum lectin with collagen- and fibrinogen-like domains that functions as an opsonin. J Biol Chem 271: 2448-2454

Michael JG (1969) Natural antibodies. Curr Top Microbiol Immunol 48: $43-62$

Mink JG, Radl J, van den Berg P, Haaijman JJ, van Zwieten MJ, Benner R (1980) Serum immunoglobulins in nude mice and their heterozygous littermates during ageing. Immunology 40: $539-545$

Miyazawa K, Inoue K (1990) Complement activation induced by human C-reactive protein in mildly acidic conditions. J Immunol 145: 650-654

Muramatsu M, Kinoshita K, Fagarasan S, Yamada S, Shinkai Y, Honjo T (2000) Class switch recombination and hypermutation require activation-induced cytidine deaminase (AID), a potential RNA editing enzyme. Cell 102: 553-563

Muramatsu M, Sankaranand VS, Anant S, Sugai M, Kinoshita K, Davidson NO, Honjo T (1999) Specific expression of activationinduced cytidine deaminase (AID), a novel member of the RNAediting deaminase family in germinal center B cells. J Biol Chem 274: $18470-18476$

Nagele EP, Han M, Acharya NK, Demarshall C, Kosciuk MC, Nagele RG (2013) Natural IgG autoantibodies are abundant and ubiquitous in human sera, and their number is influenced by age, gender, and disease. PLoS One 8: e60726

Ng PM, Le Saux A, Lee CM, Tan NS, Lu J, Thiel S, Ho B, Ding JL (2007) C-reactive protein collaborates with plasma lectins to boost immune response against bacteria. EMBO J 26: 3431-3440 
Ochsenbein AF, Fehr T, Lutz C, Suter M, Brombacher F, Hengartner H, Zinkernagel RM (1999) Control of early viral and bacterial distribution and disease by natural antibodies. Science 286: $2156-2159$

Ogden CA, Kowalewski R, Peng Y, Montenegro V, Elkon KB (2005) IGM is required for efficient complement mediated phagocytosis of apoptotic cells in vivo. Autoimmunity 38: 259-264

Prince AS, Mizgerd JP, Wiener-Kronish J, Bhattacharya J (2006) Cell signaling underlying the pathophysiology of pneumonia. Am $J$ Physiol Lung Cell Mol Physiol 291: L297-L300

Reynaud CA, Garcia C, Hein WR, Weill JC (1995) Hypermutation generating the sheep immunoglobulin repertoire is an antigenindependent process. Cell 80: 115-125

Sahu A, Pangburn MK (1994) Covalent attachment of human complement C3 to IgG. Identification of the amino acid residue involved in ester linkage formation. $J$ Biol Chem 269: 28997-29002

Schlapbach LJ, Mattmann M, Thiel S, Boillat C, Otth M, Nelle M, Wagner B, Jensenius JC, Aebi C (2010) Differential role of the lectin pathway of complement activation in susceptibility to neonatal sepsis. Clin Infect Dis 51: 153-162

Schlapbach LJ, Thiel S, Kessler U, Ammann RA, Aebi C, Jensenius JC (2011) Congenital H-ficolin deficiency in premature infants with severe necrotising enterocolitis. Gut 60: 1438-1439

Senaldi G, Ireland R, Bellingham AJ, Vergani D, Veerapan K, Wang F (1988) IgM reduction in systemic lupus erythematosus. Arthritis Rheum 31: 1213

Sidman CL, Shultz LD, Hardy RR, Hayakawa K, Herzenberg LA (1986) Production of immunoglobulin isotypes by Ly-1 + B cells in viable motheaten and normal mice. Science 232: 1423-1425

Simmen HP, Battaglia H, Giovanoli P, Blaser J (1994) Analysis of $\mathrm{pH}, \mathrm{pO} 2$ and $\mathrm{pCO} 2$ in drainage fluid allows for rapid detection of infectious complications during the follow-up period after abdominal surgery. Infection 22: 386-389

Toellner KM, Jenkinson WE, Taylor DR, Khan M, Sze DM, Sansom DM, Vinuesa CG, MacLennan IC (2002) Low-level hypermutation in $\mathrm{T}$ cell-independent germinal centers compared with high mutation rates associated with T cell-dependent germinal centers. J Exp Med 195: 383-389

TranVan Nhieu G, Clair C, Grompone G, Sansonetti P (2004) Calcium signalling during cell interactions with bacterial pathogens. Biol Cell 96: 93-101

Zaheen A, Boulianne B, Parsa JY, Ramachandran S, Gommerman JL, Martin A (2009) AID constrains germinal center size by rendering B cells susceptible to apoptosis. Blood 114: 547-554

Zar T, Yusufzai I, Sullivan A, Graeber C (2007) Acute kidney injury, hyperosmolality and metabolic acidosis associated with lorazepam. Nat Clin Pract Nephrol 3: 515-520

Zhang J, Koh J, Lu J, Thiel S, Leong BS, Sethi S, He CY, Ho B, Ding JL (2009) Local inflammation induces complement crosstalk which amplifies the antimicrobial response. PLoS Pathog 5: e1000282

Zhang J, Yang L, Anand GS, Ho B, Ding JL (2011) Pathophysiological condition changes the conformation of a flexible FBG-related protein, switching it from pathogen-recognition to host-interaction. Biochimie 93: 1710-1719

Zhang J, Yang L, Ang Z, Yoong SL, Tran TT, Anand GS, Tan NS, Ho B, Ding JL (2010) Secreted M-ficolin anchors onto monocyte transmembrane $\mathrm{G}$ protein-coupled receptor 43 and cross talks with plasma C-reactive protein to mediate immune signaling and regulate host defense. J Immunol 185: 6899-6910

Zhou ZH, Zhang Y, Hu YF, Wahl LM, Cisar JO, Notkins AL (2007) The broad antibacterial activity of the natural antibody repertoire is due to polyreactive antibodies. Cell Host Microbe 1: 51-61 